\title{
Phylogeny of the Lake Tanganyika Cichlid Species Flock and Its Relationship to the Central and East African Haplochromine Cichlid Fish Faunas
}

\author{
WAlter SAlzburger, ${ }^{1,2}$ AXel MeYer, ${ }^{3}$ SANJA BARIC,,${ }^{1,4}$ ERIK Verheyen, ${ }^{5}$ \\ AND CHRISTIAN STURMBAUER ${ }^{1,6,7}$

\begin{abstract}
${ }^{1}$ Department of Zoology and Limnology, University of Innsbruck, Technikerstrasse 25, 6020 Innsbruck, Austria ${ }^{3}$ Department of Biology, University of Konstanz, 78457 Konstanz, Germany; E-mail: axel.meyer@uni-konstanz.de ${ }^{5}$ Section Taxonomy and Biochemical Systematics, Royal Belgian Institute of Natural Sciences, Vautierstraat 29,
\end{abstract} \\ 1000 Brussels, Belgium; E-mail: verheyen@kbinirsnb.be
}

\begin{abstract}
Lake Tanganyika, the oldest of the East African Great Lakes, harbors the ecologically, morphologically, and behaviorally most complex of all assemblages of cichlid fishes, consisting of about 200 described species. The evolutionary old age of the cichlid assemblage, its extreme degree of morphological differentiation, the lack of species with intermediate morphologies, and the rapidity of lineage formation have made evolutionary reconstruction difficult. The number and origin of seeding lineages, particularly the possible contribution of riverine haplochromine cichlids to endemic lacustrine lineages, remains unclear. Our phylogenetic analyses, based on mitochondrial DNA sequences of three gene segments of 49 species ( $25 \%$ of all described species, up to 2,400 bp each), yield robust phylogenies that provide new insights into the Lake Tanganyika adaptive radiation as well as into the origin of the Central- and East-African haplochromine faunas. Our data suggest that eight ancient African lineages may have seeded the Tanganyikan cichlid radiation. One of these seeding lineages, probably comprising substrate spawning Lamprologus-like species, diversified into six lineages that evolved mouthbrooding during the initial stage of the radiation. All analyzed haplochromines from surrounding rivers and lakes seem to have evolved within the radiating Tanganyikan lineages. Thus, our findings contradict the current hypothesis that ancestral riverine haplochromines colonized Lake Tanganyika to give rise to at least part of its spectacular endemic cichlid species assemblage. Instead, the early phases of the Tanganyikan radiation affected Central and East African rivers and lakes. The haplochromines may have evolved in the Tanganyikan basin before the lake became a hydrologically and ecologically closed system and then secondarily colonized surrounding rivers. Apparently, therefore, the current diversity of Central and East African haplochromines represents a relatively young and polyphyletic fauna that evolved from or in parallel to lineages now endemic to Lake Tanganyika. [Adaptive radiation; Cichlidae; Lake Tanganyika; mitochondrial DNA sequences; molecular phylogeny; species flock.]
\end{abstract}

The three East African Great LakesVictoria, Malawi, and Tanganyika (Fig. 1)are major model systems for the study of adaptive radiation (Boulenger, 1898; Kosswig, 1947; Fryer and Iles, 1972; Meyer et al., 1990; Nishida, 1991; Meyer, 1993; Sturmbauer and Meyer, 1993; Sturmbauer et al., 1994; Kocher et al., 1995; Rossiter, 1995; Verheyen et al., 1996; Sturmbauer, 1998). Each lake contains cichlid species flocks numbering hundreds of endemic species that arose independently by way of intralacustrine spe-

\footnotetext{
${ }^{2}$ Current address: Department of Biology, University of Konstanz, 78457 Konstanz, Germany; E-mail: walter.salzburger@uni-konstanz.de

${ }^{4}$ Current address: Research Center for Agriculture and Forestry Laimburg, 39040 Auer/Ora, Italy; E-mail: Sanja.Baric@provinz.bz.it

${ }^{6}$ Current address: Department of Zoology, University of Graz, Universitaetsplat z 2, 8010 Graz, Austria; E-mail: christian.sturmbauer@uni-graz.at

${ }^{7}$ Address correspondence to this author.
}

ciation (Rensch, 1933; Kocher et al., 1993; Meyer, 1993). The most obvious differences among these species flocks are their age and complexity in terms of species number and degree of morphological specialization. With an age as great as 9 to 12 MY, the Lake Tanganyika species assemblage is by far the oldest. It is also morphologically, ecologically, and behaviorally the most complex assemblage, comprising about 200 described species in 54 genera (Fryer and Iles, 1972; Greenwood, 1984; Poll, 1986). The flocks of Lakes Victoria and Malawi consist exclusively of maternal mouthbrooders, in which females incubate eggs and protect their fry against predation in their buccal cavities (Eccles and Trewavas, 1989; Barlow, 1991; Keenleyside, 1991). In contrast, the Lake Tanganyika cichlid species assemblage encompasses a much greater diversity of brood care patterns-not only mouthbrooders of various styles but also substrate spawners, which lay their eggs on 


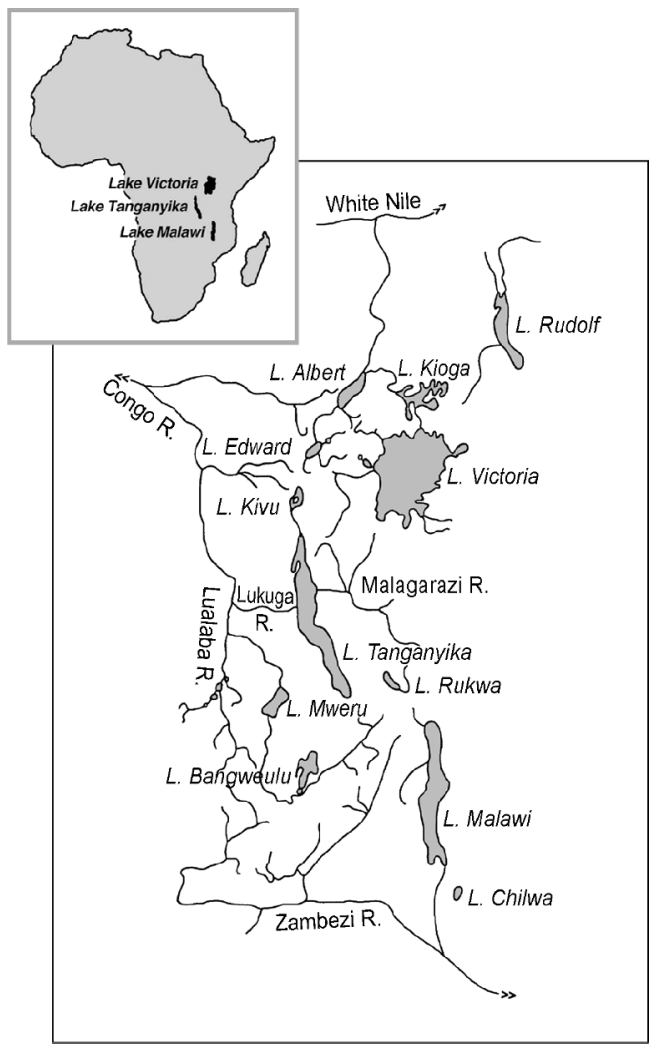

FIGURE 1. Map of eastern Africa, showing the location of the Great Lakes and the major river systems.

various substrates and protect their offspring (Kuwamura, 1986; Keenleyside, 1991). Because cichlids from Lake Tanganyika exhibit both biparental forms of mouthbrooding, as well as highly specialized modes of maternal mouthbrooding, Goodwin et al. (1998) suggested that mouthbrooding may have evolved more than once in these fishes. A similar behavioral diversity appears to have evolved among substrate breeding cichlids, for which the recruitment of brood care helpers, or dwarfism (allowing for breeding in snail shells), may serve as examples (Taborsky et al., 1986).

The long and complex geological history of the Lake Tanganyika basin is characterized by a dynamic basin morphology, as well as by fluctuations in the water level of the lake (Scholz and Rosendahl, 1988; Tiercelin and Mondeguer, 1991; Lezzar et al., 1996; Cohen et al., 1997). During the initial stages of its formation, the lake interrupted the flow of the ancient proto-Malagarazi-Congo River and progressed in step with the formation of the East African rift valley (Tiercelin and
Mondeguer, 1991). Its transformation from a riverine to a truly lacustrine environment may have already started about 20 MYA and proceeded in three major stages. The structure of the lake basin suggests that a meandering river gave rise to at least three shallow, swampy, protolakes (9-12 MYA), which progressively deepened to fuse finally into a single deep lake (5-6 MYA; Tiercelin and Mondeguer, 1991; Lezzar et al., 1996; Cohen et al., 1997).

\section{The Cichlid Species Flock of Lake Tanganyika}

Although some other teleost families (such as catfish, sardines, and nile perches) evolved small species flocks in Lake Tanganyika, cichlid fishes are by far the most diverse group. Both the smallest cichlid (Neolamprologus brevis; $3 \mathrm{~cm}$ ) and largest known cichlid species (Boulengerochromis microlepis; $80 \mathrm{~cm})$ are endemic to this lake. Poll (1986) grouped the Tanganyikan cichlids into 12 tribes (see Table 1). Representatives of four tribes are also found elsewhere in Africa. Among these, the Haplochrominiwith about 1,700 species-represents the most species-rich tribe, but only two endemic species are in Lake Tanganyika (Ctenochromis horei and $C$. benthicola), and seven other species occur in the lake and in surrounding rivers and swamps (Greenwood, 1979, 1980; Poll, 1986). The Tilapiini, which form the second most species-rich taxonomic assemblage of cichlids, have a panAfrican distribution (Klett et al., 2002). Lake Tanganyika has two endemic tilapiine species, Oreochromis tanganicae and B. microlepis. The Tylochromini are represented by a single endemic species in the lake, all remaining species of this tribe being found in West Africa (Stiassny, 1990). The tribe Lamprologini-with 84 described species, this is the most species-rich Tanganyikan lineage-also contains five riverine species found in the Congo River system (Poll, 1986; Sturmbauer et al., 1994; Stiassny, 1997). Given that the most ancestral splits in the Lamprologini are formed by lake endemics, Sturmbauer et al. (1994) suggested that the radiation of the Lamprologini started in the Tanganyikan basin before the ecosystem was hydrologically and ecologically closed, whereas the riverine species left the lake secondarily. The remaining eight tribes include species that are exclusively 
TABLE 1. Characterization of the studied species of Lake Tanganyika cichlids. Species names and tribe assignment follow the nomenclature of Poll (1986).

\begin{tabular}{|c|c|c|c|c|c|c|}
\hline Tribe & $\mathrm{s} / \mathrm{e}(\mathrm{g})$ & $\mathrm{b}$ & Species $(n)$ & Control region & cyt $b$ & ND2 \\
\hline & & & Heterochromis multiden $\mathrm{s}^{\mathrm{r}}(1)$ & - & AF428151 & AF398214 \\
\hline Bathybatini & $8 / 8(2)$ & mo & Bathybates ferox/sp. (1) & - & AF428152 & U07239a \\
\hline \multirow[t]{4}{*}{ Cyprichromini } & $6 / 6(2)$ & $\mathrm{mb}$ & & & & \\
\hline & & & Cyprichromis jumbo (3) & AF400699 & AF42815 & - \\
\hline & & & C. leptosoma $(>10)$ & - & AF428154 & AF398224 \\
\hline & & & Paracyprichromis brieni (2) & AF400700 & $\mathrm{Z} 21776^{\mathrm{a}}$ & AF398223 \\
\hline \multirow[t]{8}{*}{ Ectodini } & 30/30(13) & $\mathrm{mb}$ & Asprotilapia leptura (3) & AF400701 & Z21758 ${ }^{\mathrm{a}}$ & - \\
\hline & & & Aulonocranus dewindti (3) & AF400702 & $\mathrm{Z} 21759^{\mathrm{a}}$ & - \\
\hline & & & Callochromis macrops (-) & - & $\mathrm{Z} 21760^{\mathrm{a}}$ & $\mathrm{U} 07242^{\mathrm{a}}$ \\
\hline & & & Ectodus descampsi (2) & AF400703 & $\mathrm{Z} 21765^{\mathrm{a}}$ & - \\
\hline & & & Grammatotria lemairii (2) & AF400704 & $\mathrm{Z} 21766^{\mathrm{a}}$ & - \\
\hline & & & Microdontochromis tenuidentata (2) & AF400705 & $\mathrm{Z} 21769^{\mathrm{a}}$ & - \\
\hline & & & Ophthalmotilapia ventralis $(>10)$ & - & $\mathrm{Z}^{2} 1771^{\mathrm{a}}$ & $\mathrm{U} 07257^{\mathrm{a}}$ \\
\hline & & & Xenotilapia sima (1) & AF400706 & $\mathrm{Z} 21772^{\mathrm{a}}$ & $\mathrm{U} 07270^{\mathrm{a}}$ \\
\hline \multirow[t]{4}{*}{ Eretmodini } & $4 / 4(3)$ & $\mathrm{mb}$ & & & & \\
\hline & & & Eretmodus cyanostictus (>10) & AF400707 & AF428155 & AF398220 \\
\hline & & & Spathodus erythrodon (3) & AF400708 & AF428156 & AF398218 \\
\hline & & & Tanganicodus irsacae (3) & AF400709 & $\mathrm{Z} 21778^{\mathrm{a}}$ & AF398219 \\
\hline \multirow[t]{7}{*}{ Haplochromini } & $\sim 1,700 / 2(6)$ & $\mathrm{mb}$ & & & & \\
\hline & & & $\begin{array}{l}\text { Astatoreochromis alluaudir }(1) \\
\text { Astatotilapia burtoni } i^{\mathrm{r}}(1)\end{array}$ & $\begin{array}{l}\text { AF213618 } \\
\text { AF400710 }\end{array}$ & $\begin{array}{l}\text { AF428157 } \\
\text { Z21773 }\end{array}$ & $\begin{array}{l}\text { AF398234 } \\
\text { AF317266 }\end{array}$ \\
\hline & & & Cyclopharyn $x$ fwae $e^{\mathrm{r}}(1)$ & AF400711 & AF428158 & - \\
\hline & & & Orthochromis polyacanthus ${ }^{\mathrm{r}}(1)$ & AF400712 & AF428159 & AF398231 \\
\hline & & & Pseudocrenilabrus multicolor ${ }^{\mathrm{r}}(2)$ & AF400713 & AF428160 & AF398233 \\
\hline & & & Schwetzochromis malagarazensis ${ }^{\mathrm{r}}(2)$ & AF400714 & AF428161 & AF398232 \\
\hline & & & S. mazimeroensis ${ }^{\mathrm{r}}(2)$ & AF400715 & AF428162 & - \\
\hline \multirow[t]{10}{*}{ Lamprologini } & $84 / 79(7)$ & $\mathrm{sb}$ & & & & \\
\hline & & & $\begin{array}{l}\text { Altolamprologus calvus (3) } \\
\text { A. compressiceps (2) }\end{array}$ & $\begin{array}{c}\text { AF400716 } \\
-\end{array}$ & $\begin{array}{l}\text { Z29989 } \\
\text { AF428163 }\end{array}$ & $\begin{array}{c}- \\
\text { AF398229 }\end{array}$ \\
\hline & & & Julidochromis marlieri (3) & AF400717 & $Z 30077^{a}$ & AF398230 \\
\hline & & & Lamprologus callipterus (2) & AF400718 & Z29992a & AF398226 \\
\hline & & & L. congoensis ${ }^{\mathrm{r}}(1)$ & AF400719 & Z29993a & - \\
\hline & & & L. mocquardir $(1)$ & AF400720 & Z29995 ${ }^{\mathrm{a}}$ & AF398225 \\
\hline & & & Neolamprologus brichardi $(>10)$ & AF400721 & Z29997a & AF398227 \\
\hline & & & N. longior (1) & AF400722 & $\mathrm{Z} 30000^{\mathrm{a}}$ & - \\
\hline & & & N. toae (1) & AF400723 & $\mathrm{Z} 30002^{\mathrm{a}}$ & - \\
\hline & & & Telmatochromis bifrenatus (11) & AF400724 & $Z 30185^{\mathrm{a}}$ & AF398228 \\
\hline \multirow[t]{6}{*}{ Limnochromini } & $13 / 13(8)$ & $\mathrm{mb}$ & & & & \\
\hline & & & Benthochromis tricoti $(2)$ & AF400725 & AF428164 & - \\
\hline & & & Gnathochromis permaxillaris (3) & AF400726 & AF428165 & - \\
\hline & & & G. pfefferi (2) & AF400727 & AF428166 & $\mathrm{U} 07248^{\mathrm{a}}$ \\
\hline & & & Limnochromis auritus (1) & AF400728 & $\mathrm{Z} 21775^{\mathrm{a}}$ & AF398216 \\
\hline & & & Triglachromis otostigma (1) & AF400729 & $\mathrm{Z} 30004^{\mathrm{a}}$ & AF398217 \\
\hline \multirow[t]{3}{*}{ Perissodini } & $6 / 6(2)$ & $\mathrm{mb}$ & & & & \\
\hline & & & Perissodus microlepis (1) & AF400730 & AF428167 & AF398222 \\
\hline & & & Plecodus straeleni (2) & AF400731 & $\mathrm{Z} 21777^{\mathrm{a}}$ & AF398221 \\
\hline \multirow{3}{*}{ Tilapiini } & $\sim 250 / 2(2)$ & & & & & \\
\hline & & $\mathrm{sb}$ & Boulengerochromis microlepis (1) & - & $\mathrm{Z} 30076^{\mathrm{a}}$ & U07240a \\
\hline & & $\mathrm{mb}$ & Oreochromis tanganicae (1) & - & $\mathrm{Z} 12046^{\mathrm{a}}$ & AF317240 a \\
\hline \multirow[t]{2}{*}{ Trematocarini } & $8 / 8(2)$ & $\mathrm{mb}$ & & & & \\
\hline & & & Trematocara unimaculatum (3) & - & AF428168 & AF317268 \\
\hline \multirow{7}{*}{ Tropheini } & ) & 1110 & Cyphotilapia frontosa $(7)$ & AF400732 & AF428169 & U07247a \\
\hline & & & Lobochilotes labiatus (3) & AF400733 & AF428170 & $\mathrm{U} 07254^{\mathrm{a}}$ \\
\hline & & & Petrochromis orthognathus (4) & AF400734 & AF428171 & - \\
\hline & & & Pseudosimochromis curvifrons (2) & AF400735 & AF428172 & - \\
\hline & & & Simochromis babaulti (2) & AF400736 & $\mathrm{Z} 12045^{\mathrm{a}}$ & - \\
\hline & & & Tropheus duboisi (6) & AF400737 & $\mathrm{Z} 12041^{\mathrm{a}}$ & - \\
\hline & & & T. moorii $(>10)$ & - & Z12037a & U07267a \\
\hline \multirow[t]{2}{*}{ Tylochromini } & $\sim 20 / 1(1)$ & $\mathrm{mb}$ & & & & \\
\hline & & & Tylochromis polylepis (2) & - & AF428173 & AF398215 \\
\hline
\end{tabular}

s, number of species in the tribe; e, number of species endemic to Lake Tanganyika; g, number of genera of the tribe in Lake Tanganyika; $\mathrm{b}$, breeding style ( $\mathrm{mb}=$ mouthbrooding; $\mathrm{sb}=$ substrate breeding); $n$, number of specimens sampled.

${ }^{\mathrm{a} G e n B a n k}$ accession numbers of sequences published elsewhere.

${ }^{\mathrm{r}}$ Riverine taxa. 
found in Lake Tanganyika. These tribes occupy distinct niches or habitat types: The Bathybathini (8 species) and the Trematocarini (8 species) inhabit the deep pelagic zone, the Cyprichromini (6 species) are crustacean feeders of the shallow pelagic zone, and the Limnochromini (13 species) form an assemblage of invertebrate feeders at the deep muddy bottom. Part of the Ectodini taxa (22) are invertebrate feeders at sandy and muddy shores (8). The remaining Ectodini species, the Tropheini (23 species), and the Eretmodini (4 species) dwell in rocky habitats and feed on invertebrates or graze algae. Finally, the bizarre scale eaters (Perissodini, 6 species) feed mainly on scales of other fishes, which they sometimes imitate by mimicry.

\section{Phylogenetic Relationships of Lake Tanganyika Cichlids}

The relatively old evolutionary age of the Tanganyikan cichlid species flock is manifested not only in the unparalleled degree of morphological and ecological divergence within and among the endemic lineages, but also by the absence of morphologically intermediate species that might reveal how the lineages are interrelated (Greenwood, 1984). Moreover, diversification has been achieved mainly by allometric changes of relatively few morphological structures, rather than by true morphological innovations (Greenwood, 1984; Stiassny, 1991), thus posing considerable problems for morphology-based phylogenetic analyses. Several molecular phylogenetic studies have contributed to the current knowledge about evolutionary relationships in subgroups of Lake Tanganyika cichlids. Monophyly has been demonstrated so far for only 5 of the 12 tribes, the Tropheini (Sturmbauer and Meyer, 1992; Meyer et al., 1996; Sturmbauer et al., 1997, unpubl.; Takahashi et al., 1998), the Lamprologini (Sturmbauer et al., 1994; Takahashi et al., 1998), the Eretmodini (Verheyen et al., 1996), the Ectodini (Sturmbauer and Meyer, 1993; Takahashi et al., 1998), and the Perissodini (Takahashi et al., 1998). Studies on the adaptive radiation of cichlids in Lake Tanganyika agree that several lineages arose with dramatic speed immediately after the formation of a lacustrine habitat; this response is manifested in short branch lengths, which makes evolutionary reconstruction difficult (Nishida, 1991; Sturmbauer and
Meyer, 1993; Kocher et al., 1995). Consequently, such studies produced nonconclusive results for the relationships among the tribes. In particular, the relationships of the substrate spawning Lamprologini to seven mouthbrooding tribes-the Eretmodini, Limnochromini, Perissodini, Ectodini, Cyprichromini, Haplochromini and Tropheini-have remained unclear. A polyphyletic origin of the Lake Tanganyika species flock has been suggested, but neither the geographic origin nor the identity of relatives outside the lake is known for most endemic lineages (Fryer and Iles, 1972; Poll, 1986; Nishida, 1991, 1997). On the basis of morphological characteristics, Fryer and Iles (1972) suggested that the endemic mouthbrooding tribes have originated from riverine haplochromine colonizers. So far, the hypothesis that ancestral haplochromines have seeded the primary radiation of the majority of the mouthbrooding lineages in Lake Tanganyika remains untested. Indeed, previous phylogenetic analyses of Tanganyikan mouthbrooding lineages never included a representative sample of the haplochromine taxa, which are potential sister groups of the lake endemics. Nishida (1991) combined the seven tribes Eretmodini, Limnochromini, Perissodini, Ectodini, Cyprichromini, Haplochromini, and Tropheini into the "H-lineage" (Fig. 2a), pointing to the possibility that they evolved within the lake from the same riverine ancestor or ancestors. The study of Sturmbauer and Meyer (1993; Fig. 2b), which included the seven mouthbrooding tribes (the H-lineage), suggested a sister group relationship between the haplochromine cichlid Astatotilapia burtoni and the endemic Tanganyikan tribe Tropheini. However, this representative of the Haplochromini was not resolved as the most ancestral branch of the H-lineage. In the phylogeny of Kocher et al. (1995; Fig. 2c), based on the mitochrondrial NADH dehydrogenase subunit 2 gene (ND2), the mouthbrooding tribe Eretmodini was placed outside the $\mathrm{H}$-lineage as sister group to the substrate spawning Lamprologini. Five species of Haplochromini from Lake Malawi were resolved as sister groups to the Tropheini.

\section{Our Phylogenetic Approach}

In this study we use DNA sequences of three mitochondrial genes-1,047 bp of ND2, 
(a)
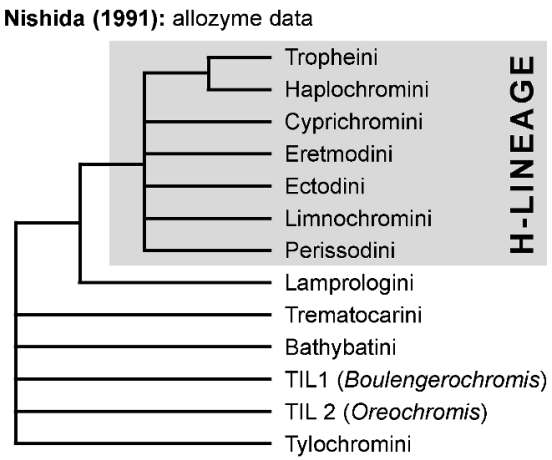

(b) Sturmbauer and Meyer (1993): mtDNA (cyt b \& control region)

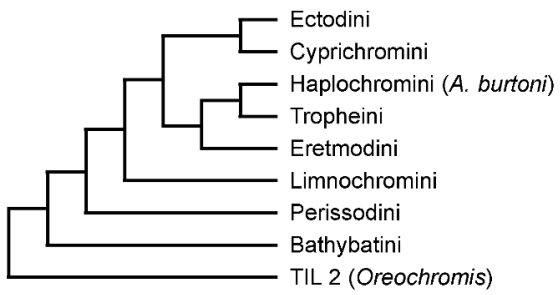

(C) Kocher et al. (1995): mtDNA (ND2)

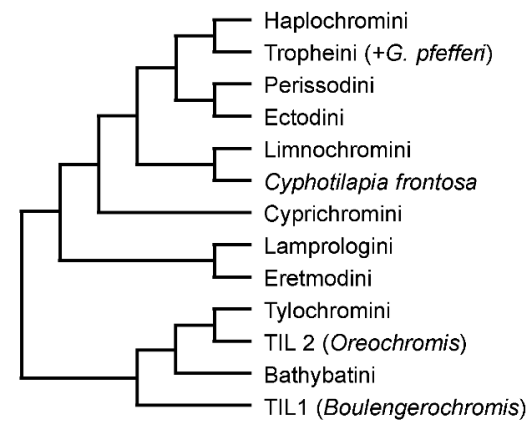

(d) Farias et al. (2000): combined data of mtDNA (16S rRNA), nDNA (TmoM27, TmoM4C4) and morphology

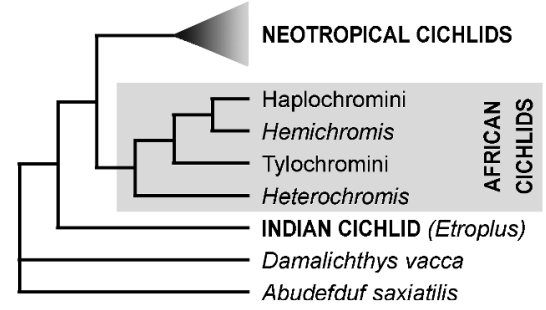

FIGURE 2. Recent phylogenetic hypothesis (redrawn) of the relationships among the Lake Tanganyika cichlid species flock. TIL1, Tilapia-lineage 1 (Boulengerochromis microlepis); TIL 2, Tilapia lineage 2 (Oreochromis tanganicae).

402 bp of cytochrome $b$ (cyt b), and 974 bp of the control region-to infer a phylogeny of the Lake Tanganyika cichlid species assemblage. With 49 species, more than $25 \%$ of all described species of Lake Tanganyikan cichlids are included in our analyses, representing all 12 tribes and 37 of the 54 genera. Our choice of taxa is based on the previous results summarized above. Of the tribes Cyprichromini, Eretmodini, Tilapiini, and Tylochromini, all described genera are included in this survey. Representatives of the missing genera in the Ectodini (five genera missing; Sturmbauer and Meyer, 1993; Takahashi et al., 1998), the Lamprologini (two genera missing; Sturmbauer et al., 1994; Takahashi et al., 1998), the Perissodini (two genera missing; Takahashi et al., 1998), and the Tropheini (one genus missing; Sturmbauer et al., unpubl.) were already shown to be members of the corresponding tribes. The only endemic haplochromine genus (Ctenochromis) was resolved within the Tropheini in a recent study (Sturmbauer et al., unpubl.). The monotypic genera Hemibates (tribe Bathybatini) and Trematochromis (tribe Trematocarini) are not included in our analyses because they are not available from current collections. However, a close morphological and ecological similarity to the remainder of their tribes has been established (Poll, 1986). For the Limnochromini, no molecular-based phylogenetic hypotheses exist. Our dataset includes only four of the eight genera of this tribe, mostly because the adaptation of these four genera to deepwater habitats made sampling difficult. The two species of the genus Greenwoodochromis and the monotypic genus Baileychromis are known only from formalinpreserved specimens. Both are assumed to occur in depths $>30-40 \mathrm{~m}$, as do the monotypic limnochromine genera Reganochromis and Tangachromis.

Our first goal was to identify the seeding lineages for the primary radiation on the basis of a linearized tree. We also wanted to address the question of the phylogenetic relationships between the Tanganyikan radiation and riverine haplochromines, such as Cyclopharynx fwae from the upper reaches of the Lualaba-Congo River and Schwetzochromis malagarazensis and S. mazimeroensis from the upper Malagarazi River. Both rivers were part of the ancient proto-MalagaraziCongo river system before the lake was formed (see Fig. 1 for a map of East African rivers and lakes). To test the hypothesis that riverine Haplochromini seeded the radiation of the mouthbrooding H-lineage (Fryer and Iles, 1972; Nishida, 1991), we also included 
in our analyses the riverine haplochromine genera Orthochromis, Pseudocrenilabrus, Astatotilapia, and Astatoreochromis. Consequently, all but one riverine haplochromine genera of this region (Thoracochromis) are included in this study. Finally, we tested the validity of the generic and tribal classification of the Tanganyikan cichlids on the basis of the obtained phylogenies.

\section{MATERIALS AND METHODS}

mtDNA from 49 species (of $>150$ specimens sampled) of cichlid fishes from all parts of Lake Tanganyika and from surrounding rivers was sequenced for as much as 2,423 bp per specimen, and the results were combined with available data from GenBank (Table 1). The West African species Heterochromis multidens was included as outgroup (Farias et al., 2000). Voucher specimens have been deposited at the Department of Zoology and Limnology, University of Innsbruck, Austria, and at the Royal Africa Museum, Tervuren, Belgium. Total DNA was extracted from ethanol-preserved fin-clips or muscle tissue by using Chelex (as outlined in Sturmbauer et al., 1998) or by digestion with proteinase $\mathrm{K}$ followed by sodium chloride extraction and ethanol precipitation (Bruford et al., 1998). Polymerase chain reaction amplification, cloning, and DNAsequencing were performed according to standard methods (Meyer et al., 1990; Sturmbauer and Meyer, 1993) by using an Air Thermo-Cycler (Idaho Tehnology) and the Big Dye sequencing chemistry on an ABI 373 A automated sequencer (Applied Biosystems). Published primers were used for amplifying ND2, cyt $b$, and the first section of the control region (Kocher et al., 1989, 1995; Meyer et al., 1990; Pääbo, 1990). For the second section of the control region we used published primers (Lee et al., 1995) and a newly designed primer (5'-TAAGAGCCCACCATCAGTTGA-3'). Sequences can be obtained from GenBank under the accession numbers listed in Table 1.

Initial alignments were obtained by Clustal W (Thompson et al., 1994). The alignment of the control region was iteratively adjusted by eye, those alternative alignments being preferred that resulted in shorter trees in parsimony analysis in which equal weightings were used for all mutations (Levinton et al., 1996). As many as 28 indels per se- quence (Astatotilapia burtoni) coding for gaps were included in the control region dataset, yielding a total length of $974 \mathrm{bp}$. The longest insertions consisted of two gaps.

\section{Phylogenetic Analyses}

Given the wide range of evolutionary ages among the species sequenced, we divided our analyses into two steps. The first step, intended to situate the Tanganyikan cichlids in a broader phylogeographic context, was based on the two relatively slowly evolving protein-coding genes, ND2 and cyt $b$. This analysis was aimed at resolving the older cladogenetic events and identifying the seeding lineages of the primary lacustrine radiation. The West African cichlid species $H$. multidens was used as outgroup. This choice was based on the findings of Farias et al. (2000; see also Farias et al., 1999; Klett et al., 2002) (Fig. 2d), who identified Heterochromis as the most ancestral genus among the African cichlids, using a combined data approach that included mitochondrial and nuclear genes and morphological traits. In a second step of analysis, we used the more variable mitochondrial control region to resolve the more recent splits, declaring the eretmodine cichlids as new outgroup according to the resulting topologies of the higher-level analysis. We also adopted a new approach, selecting sequences with similar rates of evolution for tree construction. The consideration of taxa with most similar evolutionary rates minimizes the detrimental effect of rate variation on tree reconstruction (Hillis et al., 1994).

\section{Step 1: ND2 and Cyt b}

The first analysis focused on identifying the seeding lineages and determining the most appropriate outgroup for the primary radiation of the species flock. To this end we combined ND2 sequences $(1,047 \mathrm{bp})$ with 402 bp of $c y t b$ from 33 species representing all 12 Tanganyikan tribes (Table 1 ). To test the phylogenetic congruence of the two proteincoding mitochondrial gene segments, we used the partition homogeneity test implemented in PAUP* 4.0b2a (Swofford, 2000), with 300 replicates. We point out that the power of the partition homogeneity test has been shown to be weak when one of the datasets compared is smaller than the other (Dolphin et al., 2000; Yoder et al., 2001), which 
might well be the case when $1,047 \mathrm{bp}$ of the ND2 gene is combined with 402 bp of cyt $b$. We then performed a likelihood mapping analysis with Puzzle 4.0 (Strimmer and von Haeseler, 1996, 1997) to visualize the strength of the overall phylogenetic signal in the dataset. This permutation method evaluates the likelihood supports for the three alternative topologies of multiple sets $(10,000)$ of randomly chosen taxon quartets. Likelihood frequencies of all evaluated quartet topologies are mapped on a triangle picturing a barycentric coordinate system. The triangle is partitioned into seven different zones: The central region represents completely unresolved topologies, the three corners represent fully resolved topologies, and the three intermediate regions between the corners represent partially resolved topologies. The resulting likelihood frequencies for each of the regions provide information about the strength and clarity of the phylogenetic signal in the dataset. To assess the degree of saturation of transition and transversion mutations in each codon position of the two protein-coding genes, we plotted the two types of mutations against the percentage of sequence divergence in 496 pairwise comparisons (Fig. 3), not including the outgroup $H$. multidens. Because of the degree of saturation in transition mutations in thirdcodon positions of both gene segments, we decided not to include transitions in third-codon positions of fourfold-degenerate amino acid sites. Transition mutations in the remaining data turned out to be unsaturated (Fig. 3).

Phylogenetic trees were constructed with maximum parsimony (MP) and maximum likelihood (ML) and using the computer program PAUP* 4.0b2a (Swofford, 2000). Pairwise distances were calculated by the Hasegawa-Kishino-Yano (HKY) model with a gamma distribution correction (Hasegawa et al., 1985). MP topologies were obtained by the heuristic search option and 50 replicates, applying bootstrap analyses with 1,000 pseudoreplicates as the standard measure of confidence. An unweighted MP analysis was performed by including all of the sequence data. In the weighted MP analysis, all transition mutations at third positions were weighted 1:6 for ND2 and $1: 3$ for $c y t b$ relative to transversions, based on the ML-estimated transition:transversion ratio of 6.42 for ND2 and 3.38 for cyt $b$.
Transitions at third positions of fourfolddegenerate amino acids were excluded because of their degree of saturation, as depicted in the saturation plot in Fig. 3. In an additional weighted MP analysis, C/T changes at first positions of leucine codons were treated as a fifth base and such mutations were down-weighted three times more than the nucleotide mutations that result in amino acid substitutions. The different MP topologies were compared by the nonparametric two-tailed Wilcoxon signed rank test implemented in PAUP* 4.0b2a (Swofford, 2000) (Table 2). To justify the use of an appropriate substitution model for the ML analyses, we evaluated the ML scores of the unweighted MP topology by means of a likelihood-ratio test (Sullivan et al., 1997; Huelsenbeck and Crandall, 1997) (Table 3; see also Swofford et al., 1996). We tested the Jukes-Cantor (JC; Jukes and Cantor, 1969), the Kimura-two-parameter (K2P; Kimura, 1980), the HKY, and the general time reversible (GTR; Yang, 1994) models. The degrees of freedom for the likelihood-ratio tests were determined by the differences in the number of model parameters between the different models being evaluated. The likelihood-ratio test indicated that the GTR substitution model significantly improved the $-\ln$ likelihood with respect to the HKY model $(P<0.001$; Table 3$)$. Moreover, the consideration of a $\Gamma$ distribution correction greatly improved the $-\ln$ likelihood. We thus used the GTR $+\Gamma$ model of molecular evolution with estimated values for the gamma shape parameter and for the proportion of invariable sites for ML tree construction, applying bootstrap analysis with 500 pseudoreplicates under the fast stepwise addition option in PAUP* 4.0b2a (Swofford, 2000). ML scores of all topologies were evaluated by the nonparametric Shimodaira-Hasegawa test (Shimodaira and Hasegawa, 1999) under a resamplingestimated log-likelihood (Table 2; see also Goldman et al., 2000; Buckley et al., 2001) as implemented in PAUP* 4.0b4a (Swofford, 2000). To estimate the support for distinct internal branches critical for the interpretation of the evolutionary pathways, we performed a four-cluster likelihood mapping analysis with the program PUZZLE 4.0 (Strimmer and von Haeseler, 1996, 1997). In this method, four clusters of taxa can be defined to calculate the relative likelihood 


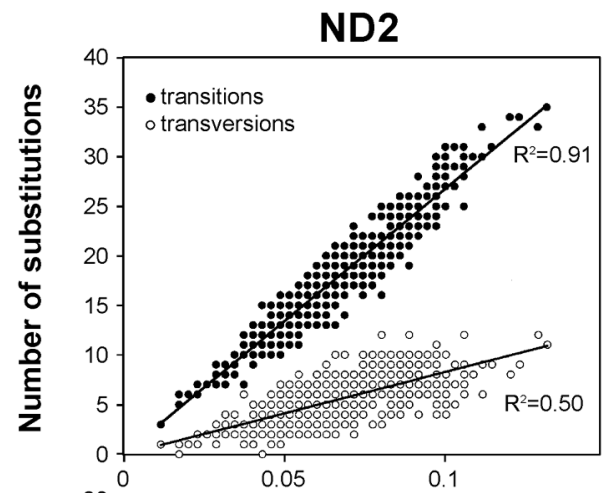

\section{Cyt $b$}

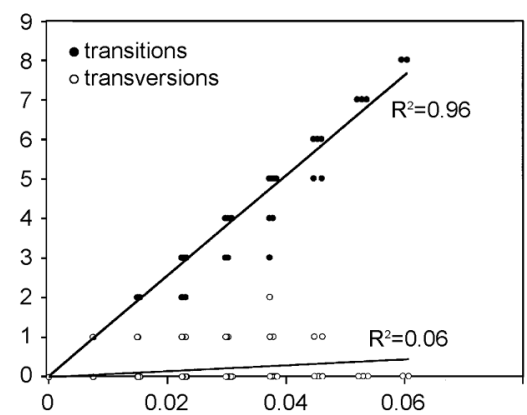

웅
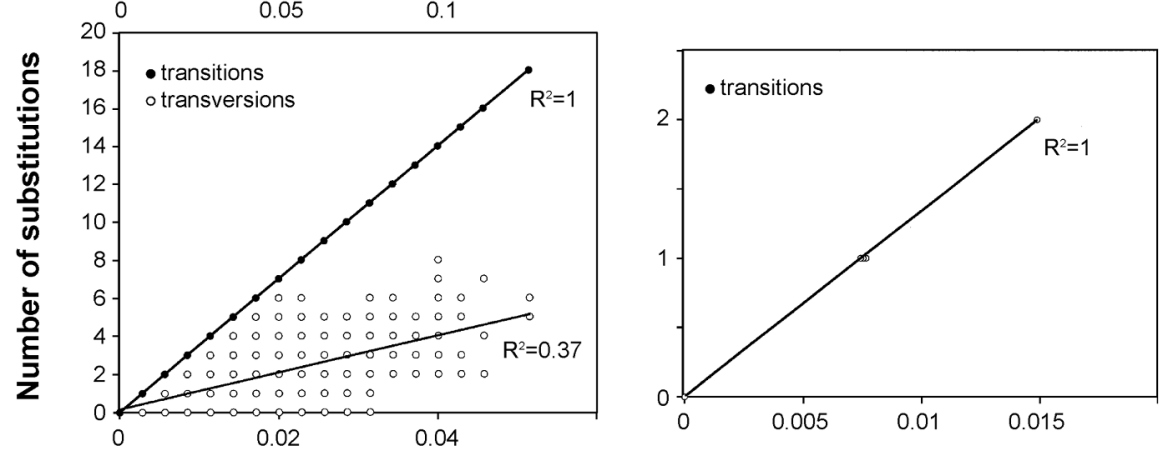

$\frac{0}{2}$
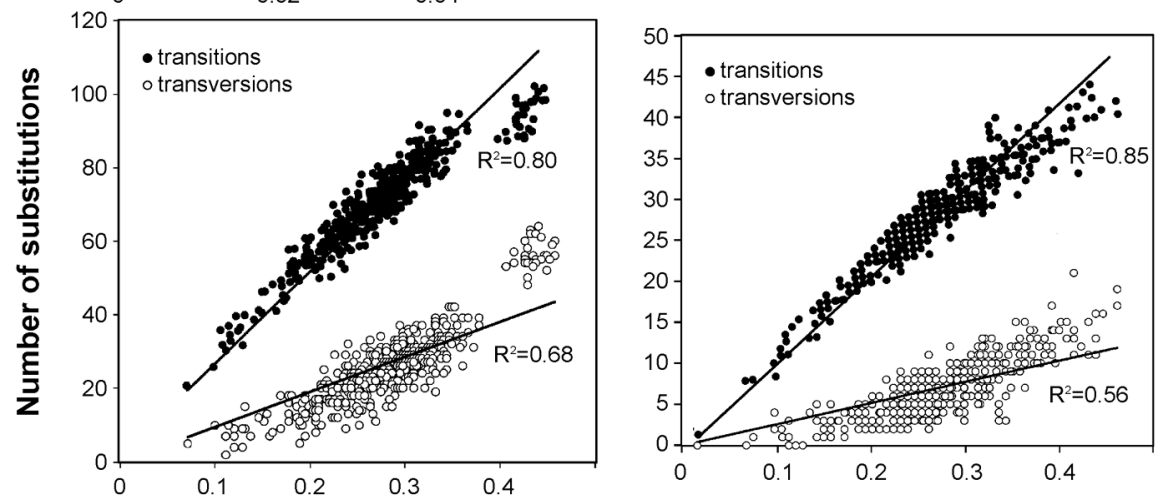

$\omega$
을
웅
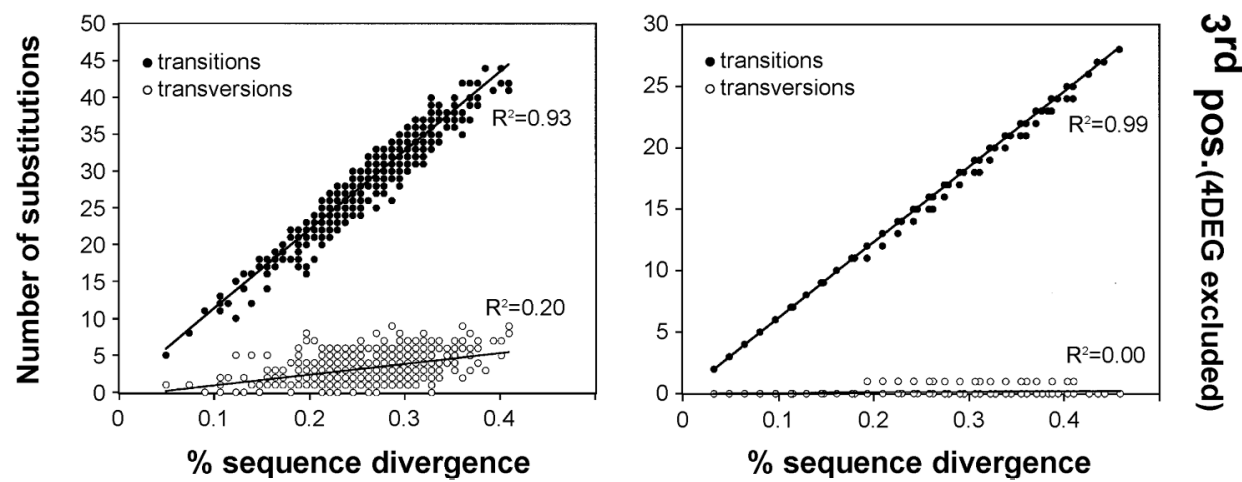

FIGURE 3. Saturation plot of transition and transversion mutations ( $y$-axis) versus percentage of sequence divergence ( $x$-axis) of 496 pairwise comparisons for the two protein-coding genes ND2 and cyt $b$. The slope and the coefficient of determination $\left(R^{2}\right)$ are depicted for each type of substitution. 
TABLE 2. Likelihood scores and MP tree lengths obtained from analyses under several weighting regimes for the dataset combining the protein-coding genes ND2 and cyt $b$ and the dataset for the control region. The topologies were evaluated against the optimal topologies by using the Shimodaira-Hasegawa (S-H) and the nonparametric two-tailed Wilcoxon signed rank test (WSR) tests, implemented in PAUP* 4.0b4a (Swofford, 2000).

\begin{tabular}{|c|c|c|c|c|c|c|}
\hline \multirow[b]{2}{*}{ Weighting strategy } & \multicolumn{3}{|c|}{ Maximum likelihood } & \multicolumn{3}{|c|}{ Maximum parsimony } \\
\hline & -ln likelihood & $\Delta \mathrm{ML}$ & S-H-test & Tree length & $\Delta \mathrm{MP}$ & WSR \\
\hline \multicolumn{7}{|l|}{$N D 2$ and $c y t b$} \\
\hline MP, uwt & $12,896.599$ & 5.777 & 0.753 & 2,552 & - & - \\
\hline $\mathrm{MP}, \mathrm{wt}$ & $12,891.608$ & 0.787 & 0.949 & 2,554 & 2 & 0.867 \\
\hline MP, 5th base, wt & $12,912.648$ & 21.826 & 0.150 & 2,568 & 16 & 0.131 \\
\hline ML & $12,890.822$ & - & - & 2,552 & 0 & 1.000 \\
\hline \multicolumn{7}{|l|}{ Control region } \\
\hline MP, uwt & $13,167.613$ & 12.791 & 0.453 & 1,409 & - & - \\
\hline MP, wt & $13,167.151$ & 12.328 & 0.468 & 1,413 & 4 & 0.382 \\
\hline MP, TV only & $13,162.149$ & 7.327 & 0.581 & 1,436 & 27 & 0.036 \\
\hline ML & $13,154.822$ & - & - & 1,429 & 20 & 0.154 \\
\hline
\end{tabular}

uwt, unweighted; wt, weighted; TV, transversions.

frequencies for each of the three possible topologies interrelating the four clusters. Likelihood frequencies are mapped on a triangle partitioned into three regions, each defining the frequency for one of the three alternative topologies. The sequences were grouped into four clusters according to the optimal MP and ML $(\mathrm{GTR}+\Gamma)$ topology (Fig. 4a).

We based the discrimination as to whether a lineage was likely to have seeded the radiation or to have arisen during the radiation itself on the use of a linearized tree. Therefore we performed the two-cluster test of Takezaki et al. (1995), using the computer program LINTRE available from the authors (Takezaki et al., 1995). The two-cluster test examines whether the average distances from any node in a given topology to the tips of the two clusters of taxa defined by this node are significantly different. Rate con- stancy is tested for all $n-1$ internal nodes in a set of $n$ sequences, excluding the outgroup(s). Sequences that are evolving too rapidly or too slowly at a high significance level $(P=0.01)$ are excluded and the test is repeated until all remaining sequences meet the significance level. Once heterogeneous sequences are eliminated, a tree for a given topology is constructed under the assumption of rate constancy, which is termed a linearized tree. In our case, all sequences showed a clocklike behavior when the HKY $+\Gamma$ model of molecular evolution was applied and none of the taxa had to be excluded for the construction of the linearized tree. Because no fossil data are available from East African lake cichlids to calibrate a molecular clock, we decided to determine the sequence of the major cladogenetic events on the basis of a relative time scale.

TABLE 3. Likelihood-ratio test for different substitution models based on unweighted MP topologies for the dataset combining the protein-coding genes ND2 and cyt $b$ and that for the control region (see text for details).

\begin{tabular}{|c|c|c|c|c|}
\hline Substitution model & -ln likelihood & Comparison & $\Delta \mathrm{ML}$ & $P$ \\
\hline \multicolumn{5}{|l|}{$N D 2$ and $c y t b$} \\
\hline $\mathrm{JC}$ & $14,448.151$ & - & - & - \\
\hline $\mathrm{K} 2 \mathrm{P}$ & $13,355.641$ & JC vs. K2P & $1,092.510$ & $<0.001$ \\
\hline HKY & $13,152.666$ & K2P vs. HKY & 202.975 & $<0.001$ \\
\hline GTR & $13,126.389$ & HKY vs. GTR & 26.277 & $<0.001$ \\
\hline GTR $+\Gamma$ & $12,910.103$ & GTR vs. GTR $+\Gamma$ & 194.727 & $<0.001$ \\
\hline \multicolumn{5}{|l|}{ Control region } \\
\hline JC & $8,661.053$ & - & - & - \\
\hline $\mathrm{K} 2 \mathrm{P}$ & $8,413.037$ & JC vs. K2P & 248.016 & $<0.001$ \\
\hline HKY & $8,287.339$ & K2P vs. HKY & 128.698 & $<0.001$ \\
\hline GTR & $8,262.790$ & HKY vs. GTR & 24.549 & $<0.001$ \\
\hline $\mathrm{GTR}+\Gamma$ & $8,084.431$ & GTR vs. GTR $+\Gamma$ & 202.908 & $<0.001$ \\
\hline
\end{tabular}


(a)

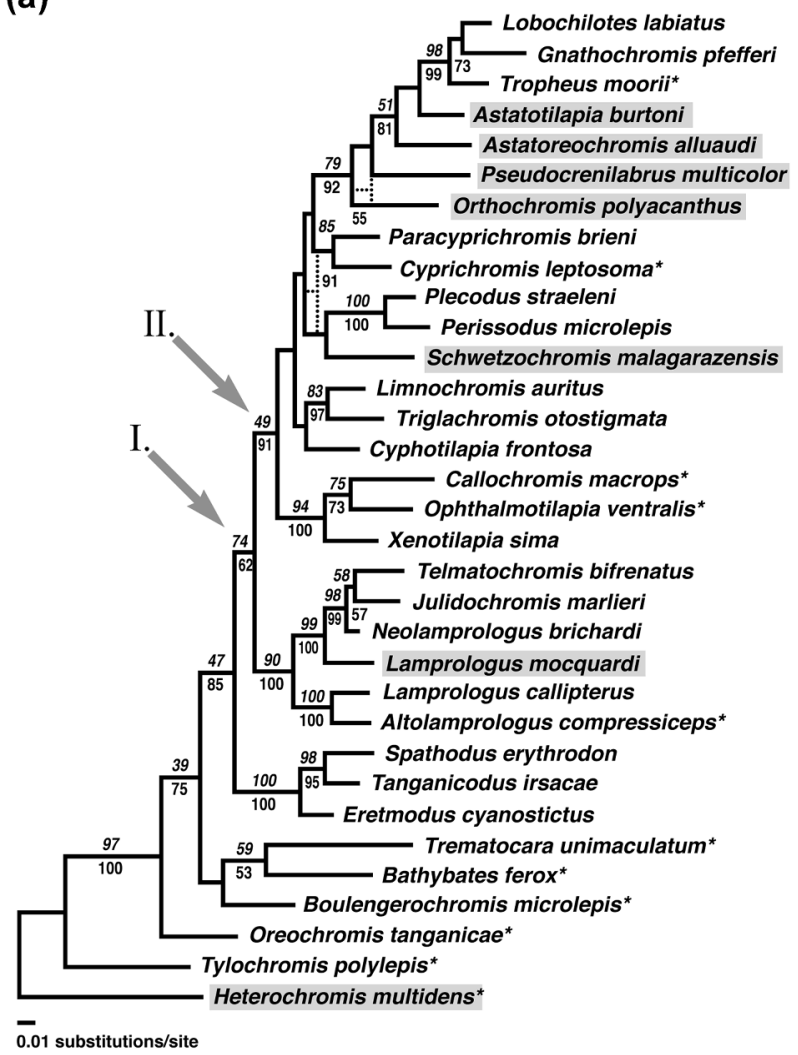

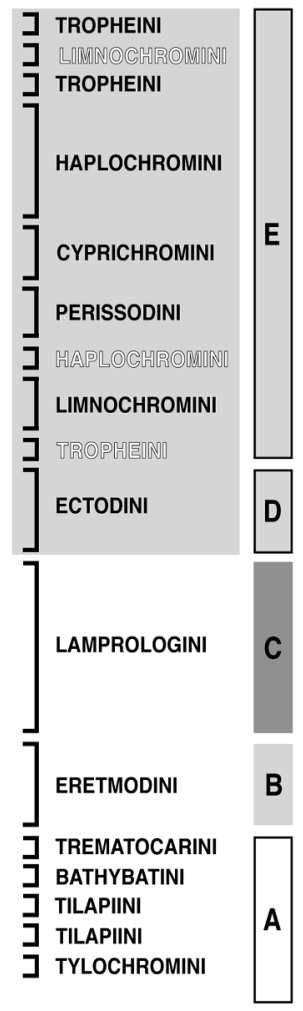

(b)
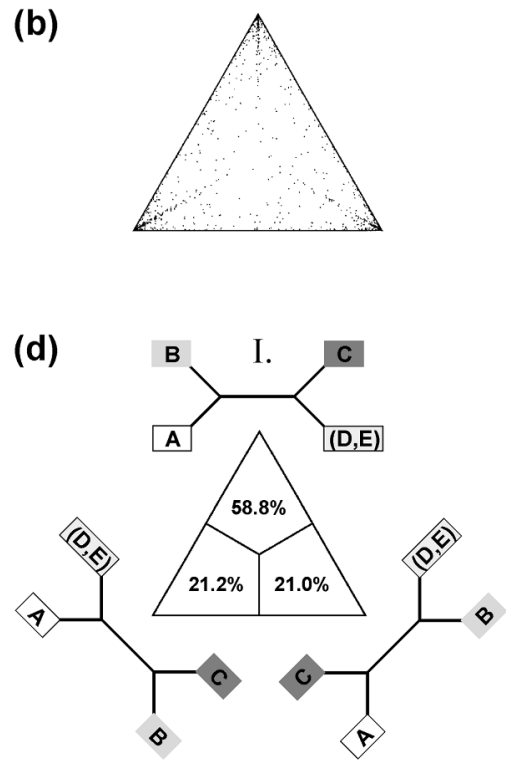

(c)

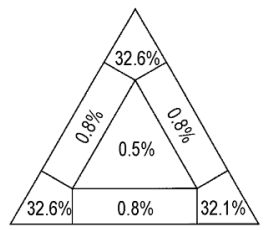

(e)

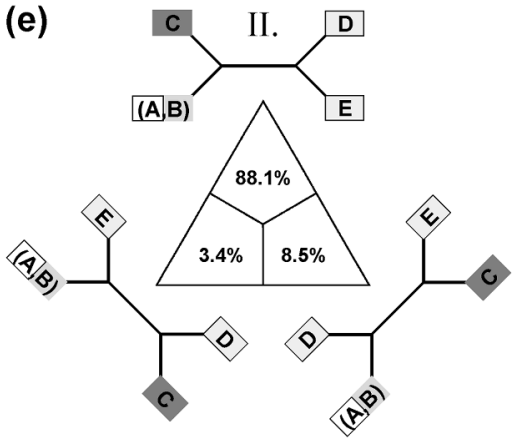




\section{Step 2: Control Region}

In the second step of analyses we focused on the radiation itself, using the entire mitochondrial control region of 40 taxa. The tribes Trematocarini, Tylochromini, Bathybatini, and Tilapiini were excluded from this analysis, because there was strong support for ancestral position for them in the higher-level analysis (Fig. 4). Instead, we used the eretmodine cichlids Eretmodus cyanostictus, Tanganicodus irsacae, and Spathodus erythrodon as a new outgroup. Again, a likelihood mapping analysis was performed with PUZZLE 4.0 (Strimmer and von Haeseler, 1996, 1997) to assess the strength of the overall phylogenetic signal in the dataset. A saturation plot was constructed for the whole dataset. MP and ML topologies were obtained by the same search parameters as in step 1, and pairwise distances were calculated by using the HKY $+\Gamma$ model (Hasegawa et al., 1985). In MP, gaps were treated as fifth base, whereas in ML, gaps were treated as missing data. For MP analyses, various weighting regimes were evaluated by means of the nonparametric two-tailed Wilcoxon signed rank test with PAUP* 4.0b2a (Swofford, 2000); significantly different ML trees were identified by the Shimodaira-Hasegawa test under a resampling-estimated log-likelihood implemented in the same program (Table 2). To identify the most appropriate substitution model for ML analyses, we tested the JC, K2P, HKY, and GTR models with and without rate variation by means of a likelihoodratio test (Table 3). Again, GTR $+\Gamma$ turned out to be the appropriate model and was thus used. To link the Tanganyikan and riverine Haplochromini to the species flocks of Lakes Malawi and Victoria, six additional
TABLE 4. Species names and GenBank accession numbers of the control region sequences of the haplochromine cichlids included from Lake Victoria and Malawi.

\begin{tabular}{llc}
\hline Taxon & Accession No. & Reference \\
\hline $\begin{array}{c}\text { Lake Victoria } \\
\text { Haplochromis } \\
\text { lividus } \\
\begin{array}{c}\text { Neochromis } \\
\text { nigricans }\end{array}\end{array}$ & AF213523 & Nagl et al., 2000 \\
$\begin{array}{c}\text { Lake Malawi } \\
\text { Labeotropheus } \\
\text { trewavasae }\end{array}$ & AF213623 & Nagl et al., 2000 \\
$\begin{array}{c}\text { Lethrinops } \\
\text { auritus } \\
\text { Pseudotropheus } \\
\text { msobo }\end{array}$ & AF12551 & Lee et al., 1995 \\
$\begin{array}{c}\text { Cyrtocara } \\
\text { moorii }\end{array}$ & $\mathrm{U} 12554$ & Nagl et al., 2000 \\
\hline
\end{tabular}

sequences from GenBank were included in the dataset for additional analyses (Table 4).

To reduce the deterioration of the phylogenetic signal caused by increased levels of homoplasy, the result of the arbitrary choice of taxa (Moritz et al., 1987), we tested the relative rates of base substitutions in the control region for 39 taxa. The DNA sequence of Astaoreochromis alluaudi obtained from GenBank was not included in this analysis. We performed the branch length test of Takezaki et al. (1995), using their computer program LINTRE (Table 5). The measured rate of molecular evolution has been shown to be linear whenever the maximum percentage of genetic divergence ( $p$-distance) was $<15 \%$ (Brown, 1983). After excluding 12 taxa according to the branch length test $(P<0.01)$, the maximum $p$-value decreased to $13.1 \%$, compared with $18.4 \%$ for the complete dataset. By excluding sequences with

FIGURE4. (a) Depiction of ML $($ GTR $+\Gamma)$ tree of Lake Tanganyika cichlid s based on ND2 and $c y t b$ DNA sequences (declaring H. multidens as outgroup). Numbers above the branches (in italics) are ML bootstrap estimates; numbers below the branches are the corresponding MP bootstrap estimates (values $<50 \%$ are not shown). MP groupings differing from ML are indicated with dotted lines. Names of the corresponding tribes are depicted on the left; the redefined $\mathrm{H}$-lineage is highlighted with a gray box. Riverine taxa also are marked with a gray box, and taxa not shared with the control-region analyses are indicated with asterisks. (b, c) Results of the likelihood mapping analysis (Strimmer and von Haeseler, 1997), represented as triangles. Values at the corners in (c) indicate the percentages of fully resolved phylogenies for all possible quartets; values at the lateral sections of the triangle are the percentages of partially resolved quartet phylogenies; and the number in the center of the triangle represents the percentage of unresolved quartet topologies. (d, e) Four-cluster likelihood mapping analysis (Strimmer and von Haeseler, 1997). Sequences were split into four disjointed groups, each defining an internal branch under evaluation that is crucial for identification of the onset of the primary radiation of the Lake Tanganyika cichlid species flock. The internal branches under evaluation are identified by roman numbers (I, II) on the phylogeny and at the corresponding triangle. The groupings are indicated by A, B, C, D, and E in (a). The corners of the triangle show the percentage of support for each of the three alternative topologies for the four clusters under evaluation. 
TABLE 5. Results of the branch-length test (Takezaki et al., 1995), obtained with the computer program LINTRE (E, taxa excluded from further analyses; R, taxa reincluded in an additional step).

\begin{tabular}{|c|c|c|c|}
\hline \multirow[b]{2}{*}{ Taxon } & \multicolumn{3}{|c|}{$z$-value } \\
\hline & Control region & cyt $b$ & Combined data set \\
\hline Altolamprologus calvus & 2.60 & 0.18 & 0.49 \\
\hline Asprotilapia leptura & 0.55 & 0.32 & 1.22 \\
\hline Astatotilapia burtoni & 1.69 & 0.24 & 0.26 \\
\hline Aulonochromis dewindti & 1.59 & 0.32 & 0.86 \\
\hline Benthochromis tricoti & 3.01 & 0.71 & E \\
\hline Cyclopharynx fwae & 4.25 & 2.32 & $\mathrm{R}$ \\
\hline Cyphotilapia frontosa & 6.15 & 4.35 & $\mathrm{R}$ \\
\hline Cyprichromis jumbo & 5.58 & 0.94 & $\mathrm{E}$ \\
\hline Ectodus descampsi & 3.05 & 1.02 & $\mathrm{E}$ \\
\hline Eretmodus cyanostictus & outgroup & outgroup & outgroup \\
\hline Gnathochromis permaxillaris & 4.40 & 1.25 & E \\
\hline G. pfefferi & 4.25 & 2.72 & $\mathrm{R}$ \\
\hline Grammatotria lemairii & 1.76 & 0.03 & 0.92 \\
\hline Julidochromis marlieri & 1.70 & 0.15 & 0.09 \\
\hline Lamprologus callipterus & 1.47 & 0.85 & 0.31 \\
\hline L. congoensis & 0.64 & 0.54 & 0.41 \\
\hline L. mocquardi & 1.10 & 0.39 & 0.04 \\
\hline Limnochromis auritus & 0.01 & 1.93 & 1.54 \\
\hline Lobochilotes labiatus & 2.50 & 0.87 & 0.02 \\
\hline Microdontochromis tenuidentata & 1.09 & 0.18 & 0.88 \\
\hline Neolamprologus brichardi & 0.64 & 1.60 & 0.22 \\
\hline N. longior & 4.34 & 1.40 & E \\
\hline N. toae & 2.87 & 1.51 & $\mathrm{E}$ \\
\hline Orthochromis polyacanthus & 0.42 & 2.22 & 0.17 \\
\hline Paracyprichromis brieni & 1.87 & 1.36 & 2.14 \\
\hline Perissodus microlepis & 2.10 & 0.68 & 0.45 \\
\hline Plecodus straeleni & 0.75 & 0.15 & 1.07 \\
\hline Petrochromis orthognathus & 1.90 & 0.18 & 0.03 \\
\hline Pseudocrenilabrus multicolor & 0.45 & 2.37 & 2.04 \\
\hline Pseudosimochromis curvifrons & 1.10 & 0.94 & 0.01 \\
\hline Schwetzochromis malagarazensis & 5.13 & 1.12 & $\mathrm{R}$ \\
\hline S. mazimeroensis & 4.34 & 0.98 & $\mathrm{E}$ \\
\hline Simochromis babaulti & 1.90 & 0.17 & 1.03 \\
\hline Spathodus erythrodon & outgroup & outgroup & outgroup \\
\hline Tanganicodus irsacae & outgroup & outgroup & outgroup \\
\hline Telmatochromis bifrenatus & 1.22 & 0.90 & 0.62 \\
\hline Triglachromis otostigma & 0.34 & 1.74 & 0.75 \\
\hline Tropheus duboisi & 4.84 & 1.60 & $\mathrm{E}$ \\
\hline Xenotilapia sima & 2.53 & 0.25 & 1.19 \\
\hline
\end{tabular}

uneven mutation rates, we were able to objectively reduce the number of sequences in our dataset. This way, we retained only those representatives of each tribe that met the criteria for obtaining optimum phylogenetic signal for the branches interrelating the tribes. In this analysis, 27 sequences of the control region were combined with $402 \mathrm{bp}$ of the $c y t b$ gene, because most corresponding $c y t b$ sequences were already available from earlier studies (Sturmbauer and Meyer, 1993; Sturmbauer et al., 1994). In the cyt $b$ gene segment, one sequence (from Cyphotilapia frontosa) showed a markedly different rate of base substitution according to the branch length test (Table 5). In the combined dataset, after excluding all sequences of an uneven rate of base substitution, the relative rates of base substitutions of all remaining sequences were not significantly different (Table 5). The phylogenetic congruence of the two genes was again tested by the partition homogeneity test with PAUP* 4.0b2a (Swofford, 2000). We then performed MP and ML analyses, weighting transitions 1:2 relative to transversions in MP (based on the ML estimate of the transition:transversion ratio of 1.6), and using the GTR $+\Gamma$ model for ML. Finally, four species showing an uneven mutation rate in the control region (Cyclopharynx fwae, Cyphotilapia frontosa, Gnathochromis pfefferi, and Schwetzochromis malagarazensis) were reincluded in the MP analysis. Phylogenetic placement of these species was achieved in 
an additional phylogenetic analysis, in which the consensus tree topology obtained without them was constrained. This procedure allowed derivation of a more comprehensive, albeit preliminary, phylogenetic hypothesis for the Lake Tanganyika species assemblage.

\section{RESULTS}

\section{Step 1: ND2 and Cyt b}

Novariation in length was detected among ND2 and cyt $b$ sequences. In ND2, 366 of the 1,047 nucleotide positions were parsimonyinformative, 279 of which $(76 \%)$ affected third-codon positions. The HKY $+\Gamma$ sequence divergences in the ingroup ranged from 0.57786 (Tylochromis polylepis-Orthochromis polyacanthus) to 0.04795 (Neolamprologus brichardi-Telmatochromis bifrenatus). In cyt $b, 112$ of the 402 positions were parsimonyinformative, and 105 of these $(93 \%)$ ) occurred in third-codon positions. The HKY $+\Gamma$ distances were between 0.50696 (Tylochromis polylepis-Pseudocrenilabrus multicolor) and 0.00514 (Tanganicodus irsacae-Spathodus erythrodon). The partition homogeneity test indicated phylogenetic congruence between the two protein-coding genes $(P=0.17)$. Likelihood mapping resulted in $97.1 \%$ fully resolved quartets, pointing to a strong phylogenetic signal in the dataset (Fig. $4 b, c$ ). The chi-square test of homogeneity of base frequencies across taxa (as implemented in PAUP*), evaluating informative sites only, resulted in $\chi_{(96)}^{2}=121.076(P=0.043)$ for ND2 and $\chi_{(96)}^{2}=1.95(P=1.000)$ for $c y t b$. Both values do not reject homogeneity of base frequencies at $P=0.01$.

Unweighted MP analysis yielded a single most-parsimonious tree [2,552 steps; consistency index excluding uninformative sites (CI; Kluge and Farris, 1969): 0.42; retention index (RI; Farris, 1989): 0.47], whereas the weighted MP analysis yielded a tree of 2,554 steps. A topology with 2,568 steps was obtained from the weighted analysis that treated $\mathrm{C} / \mathrm{T}$ changes at first positions of leucine codons as a fifth base (see Table 2). The bootstrap supports for the unweighted parsimony analysis are depicted on the corresponding branches in Fig. 4a. In all MP topologies, Tylochromis polylepis was resolved as the most ancestral lineage of the Tanganyikan taxa. The next branches were occupied by Oreochromis tanganicae, Boulengerochromis microlepis, Bathybates ferox, and Trematocara unimaculatum, but their branching order differed in the various MP trees obtained. The three representatives of the Eretmodini formed the next branch, followed by the Lamprologini and the remaining representatives of the $\mathrm{H}$-lineage. Cyphotilapia frontosa was consistently placed outside the Tropheini, being resolved as a separate lineage, more closely related to the Limnochromini; however, bootstrap support for this was low. In accordance with previous results (Kocher et al., 1995), Gnathochromis pfefferi, which is presently considered to be a member of the tribe Limnochromini (Poll, 1986), was placed among the Tropheini. The representatives of the Haplochromini were not resolved monophyletically: Although Schwetzochromis appeared to be a separate, more ancestral lineage, more closely related to the Perissodini, the Astatotilapia invariably appeared as the sister genus to the Tropheini (as in previous analyses).

In the optimal ML topology (depicted in Fig. 4a), Tylochromis polylepis was resolved as the most ancestral lineage, followed by Oreochromis tanganicae. Boulengerochromis microlepis, Bathybates ferox, and Trematocara unimaculatum branched next, with Boulengerochromis as the most ancestral split, albeit with low bootstrap support. The Eretmodini were resolved as sister group to the Lamprologini and the remainder of the H-lineage. Again, Cyphotilapia frontosa was placed outside the Tropheini, and Gnathochromis pfefferi clustered within the Tropheini. Schwetzochromis malagarazensis was resolved as a separate lineage of the Haplochromini, Astatotilapia as sister to the Tropheini. The four-cluster likelihood mapping analyses evaluating the likelihood supports for two crucial branches (labeled I and II in Fig. 4a) yielded 58.8\% (Fig. 4d) for branch I, 88.1\% (Fig. 4e) for branch II. This robust support for this particular branching order corroborates the validity of the Eretmodini as outgroup for the analyses of the primary lacustrine radiation (branch I) as well as the placement of the Lamprologini as sister group to the remaining lineages of the $\mathrm{H}$-lineage (branch II). These values correspond to the bootstrapping values obtained with MP, although the bootstrap support for branch II was weaker in ML (Fig. 4a). The strong support for branch II in the four-cluster likelihood mapping with respect to ML itself might be the result of grouping the taxa into 


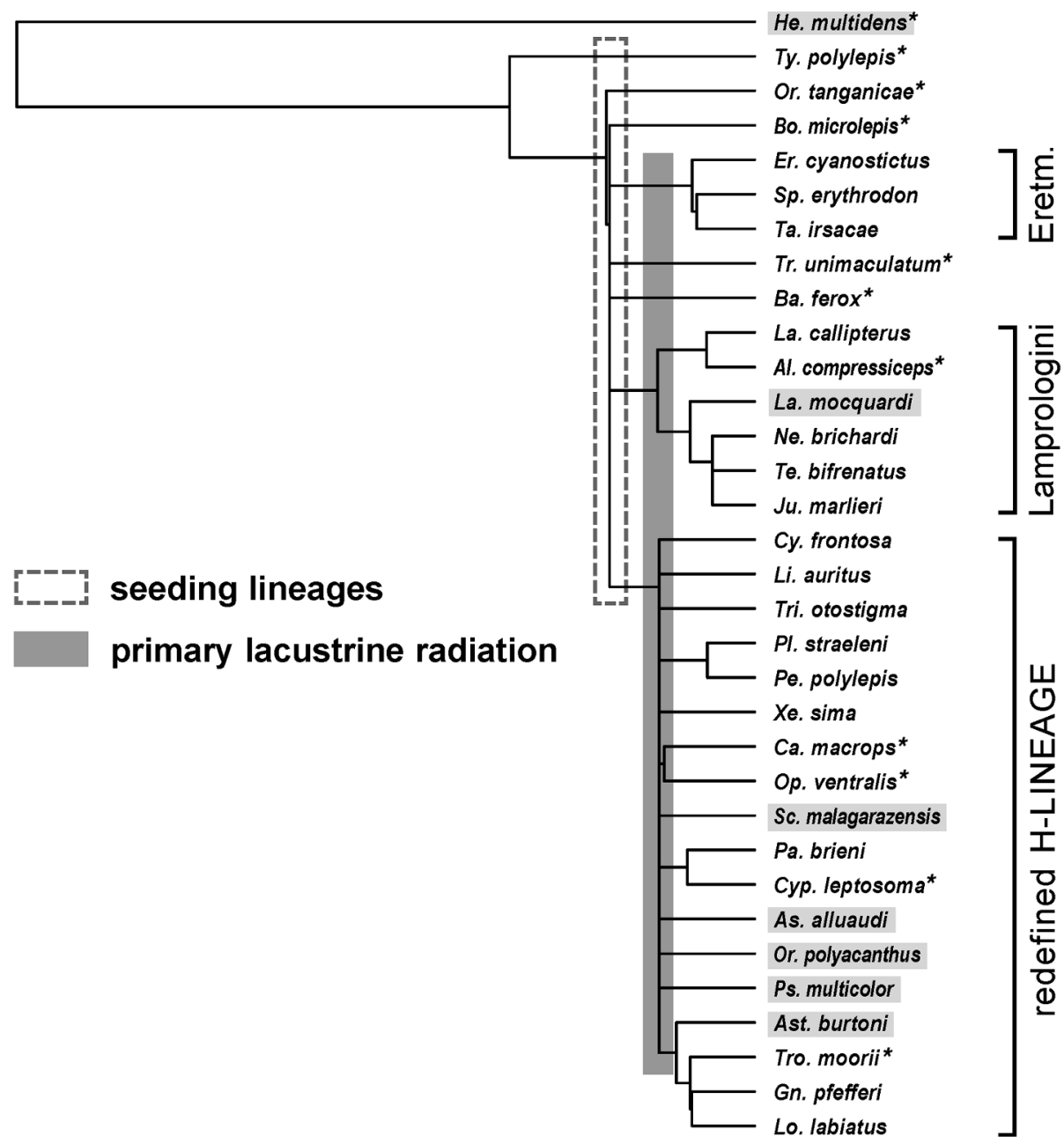

FIGURE 5. Linearized tree based on ND2 and cyt $b$ DNA sequences constructed with the two-cluster test of the LINTRE program package (Takezaki et al., 1995), identifying two series of cladogenetic events in the Lake Tanganyika cichlid species flock. Riverine taxa are marked with a gray box; taxa not shared with the control-region analyses are indicated with asterisks.

four clusters based on the optimal MP and ML topology and of using four-cluster likelihood mapping. Each of the 10,000 taxon quartets evaluated consists of four randomly chosen representatives (one of each of the four clusters), which makes this method less dependent on the selection of taxa. Because topologies combining representatives of two or more clusters on one of the four branches are not valid, this method focuses on the branches interrelating the predefined clusters. Alternative arrangements of taxon clusters are thus effectively excluded.

The linearized tree, constructed with the LINTRE package (Takezaki et al., 1995), clearly identified two series of cladoge- netic events in the Lake Tanganyika cichlids species flock (Fig. 5). These two series were delineated from clusters of very short branches, whereas gradual evolutionary processes were indicated by longer internal branches.

\section{Step 2: Control Region}

In the second analysis we focused on the Tanganyikan radiation itself. The tribes Trematocarini, Tylochromini, Bathybatini, and Tilapiini were excluded from this analysis, their ancestral position in the phylogeny having already been strongly supported by the higher-level analysis (see Fig. 4). In the 
control region, 294 of the 974 nucleotide positions were parsimony-informative. The HKY $+\Gamma$ distances were between 0.28028 (Neolamprologus longior-Gnathochromis pfefferi) and 0.01217 (Lamprologus congoensis-L. mocquardi). The chi-square test of homogeneity of base frequencies across sequences resulted in $\chi_{(135)}^{2}=78.21(P=0.999)$ for not rejecting homogeneity of base frequencies. The likelihood mapping analysis revealed a percentage of fully resolved quartet topologies to be $96.3 \%$ (Fig. 6b), pointing to an excellent overall phylogenetic signal in the dataset.

The unweighted MP analysis yielded 216 most-parsimonious trees of 1,409 steps in length. The Lamprologini were placed as sister group to the remaining endemic Tanganyikan and riverine lineages [bootstrap support $(B S)=31$ ]. The branching order of these endemic Tanganyikan and riverine lineages was not resolved in the strict MP topology. However, Cyphotilapia frontosa was consistently placed outside the Troheini, as sister group to the Perissodini $(B S=42)$; Gnathochromis pfefferi clustered within the Tropheini; and a putative member of the Limnochromini (Benthochromis tricoti) was placed outside the Limnochromini, sister to Cyphotilapia and the Perissodini (BS $=19$ ). The weighted MP tree (1,413 steps; yielding a better -ln likelihood than the unweighted MP trees; results not shown) resolved the Lamprologini as sister group to the remainders of the H-lineage" $(\mathrm{BS}=47)$. A clade comprising the Limnochromini, sister group to $C$. frontosa and the two representatives of the Perissodini (BS = 41), branched off next. Then followed a clade comprising the Cyprichromini with Benthochromis tricoti $(\mathrm{BS}=18)$, followed by the Ectodini. Two haplochromine lineages (Astatoreochromis and Schwetzochromis; and Pseudocrenilabrus, Cyclopharynx, and Orthochromis) were resolved as sister group to a clade comprising Astatotilapia and the Tropheini (including Gnathochromis pfefferi) (BS = 80).

In the ML tree (not shown), the Lamprologini were again placed outside the $\mathrm{H}$-lineage. Within the $\mathrm{H}$-lineage, the Ectodini and Schwetzochromis occupied the most ancestral branch, followed by a clade comprising the Cyprichromini (with Benthochromis) and the Limochromini, sister group to the Perissodini and Cyphotilapia. The next branch was formed by the Haplochromini/
Tropheini assemblage. The inclusion of six haplochromine taxa from lakes Victoria and Malawi (Fig. 6a) did not change the topologies obtained without them. These taxa were consistently placed as sister group to the Tropheini, with Astatotilapia burtoni sister to the two representatives from LakeVictoria.

The MP topology based on the reduced dataset (27 taxa; combining the control region with cyt $b$; partition homogeneity test: $P=0.95)$, again identified the Lamprologini as sister group to the $\mathrm{H}$-lineage ( $\mathrm{BS}=55$ ). Within the H-lineage, the Limnochromini formed a clade, as did the Cyprichromini with the Perissodini, and the Ectodini formed the sister group to the Tropheini/ Haplochromini. The branching order among these clades was not resolved in the strict consensus topology. Phylogenetic placement of four taxa that were included after constraining the strict MP consensus topology is depicted in Fig. 7a. In the ML tree, the Ectodini occupied the most ancestral branch within the H-lineage. The Cyprichromini and the Limochromini branched off next, sister group to the Perissodini and Cyphotilapia, and then the Haplochromini/Tropheini assemblage.

\section{DISCUSSION}

A polyphyletic origin of the radiation of Lake Tanganyika cichlid fishes has long been suggested, given that 4 of the 12 tribes have members that are found outside the lake (Poll, 1986; Nishida, 1991). However, neither the geographic origin nor the identity of sister groups outside the lake is known for the majority of the endemic lineages. Investigators have so far assumed that several endemic mouthbrooding tribes originated from riverine haplochromine colonizers (Fryer and Iles, 1972; Nishida, 1991). Earlier studies indeed demonstrated a close relationship of haplochromine species to part of the Tanganyikan lineages (Meyer et al., 1991; Nishida, 1991; Meyer, 1993; Sturmbauer and Meyer, 1993; Kocher et al., 1995). The analysis presented here is the first to include several riverine haplochromines of the genera Orthochromis, Schwetzochromis, Cyclopharynx, Pseudocrenilabrus, Astatotilapia, and Astatoreochromis (Greenwood, 1979, 1980; Poll, 1986), all of which are potential sister groups to lake endemics. The inclusion of these taxa allowed us to test the current 
(a)
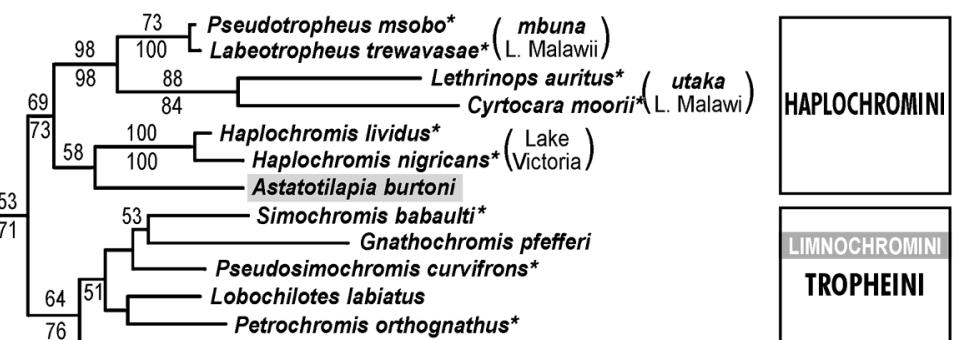

TROPHEINI

Tropheus duboisi* Orthochromis polyacanthus

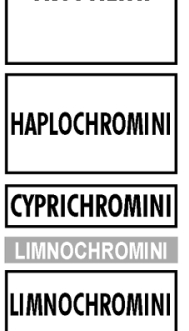

PERISSODINI

TROPHEINI Cyphotilapia frontosa

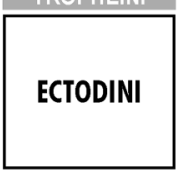

HAPLOCHROMINI Schwetzochromis malagarazensis
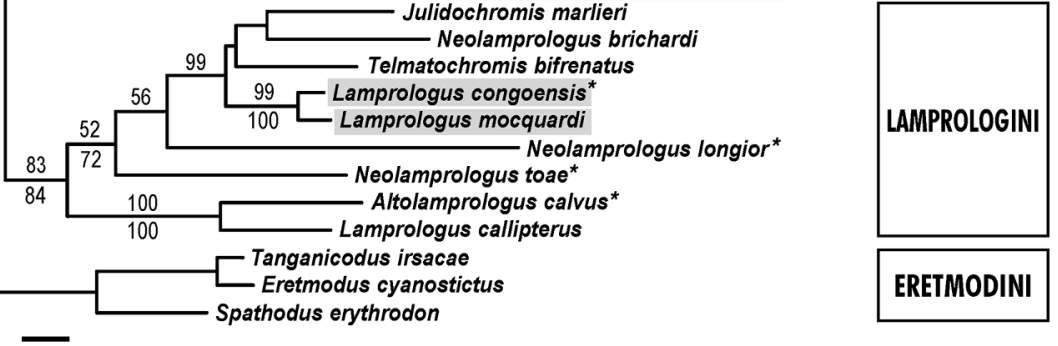

ERETMODINI

0.01 substitutions/site

(b)

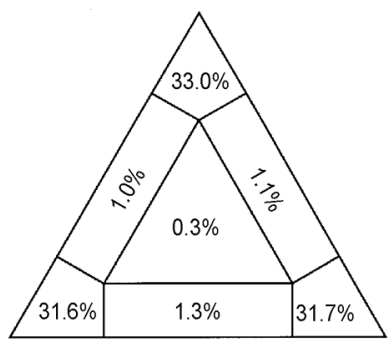

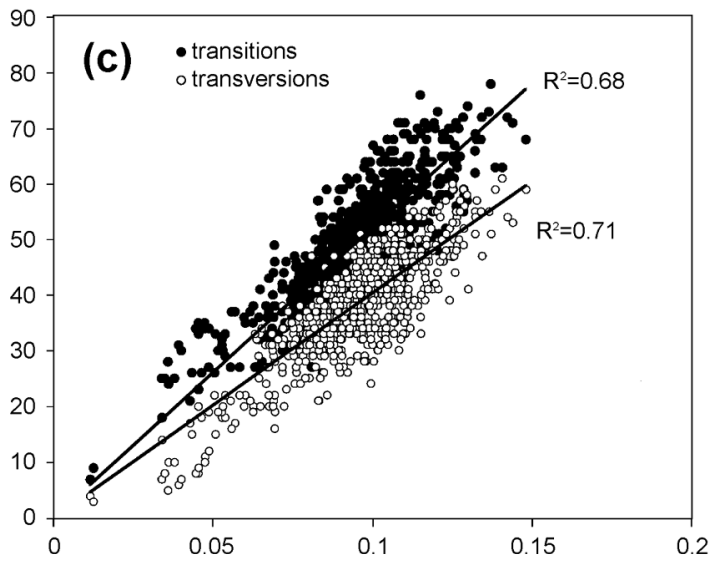


hypothesis that ancestral haplochromine colonizers would have seeded the primary radiation of most mouthbrooding lineages in Lake Tanganyika.

\section{Identity and Geographic Origin of Ancestral Lineages Seeding the Tanganyika Radiation}

Our evolutionary reconstruction, based on the linearized tree method (Takezaki et al., 1995), identified two series of cladogenetic events affecting the Lake Tanganyika cichlid species assemblage (Fig. 5). The first series of cladogenetic events involving the lineages that seeded the Lake Tanganyika radiation (dashed box in Fig. 5) is likely to have taken place at an early stage of the lake formation, when the protolake (or lakes) were much shallower (see Tiercelin and Mondeguer, 1991). The second series of cladogenetic events delineated from the linearized tree (gray box in Fig. 5) appears to represent the primary radiation taking place in the lacustrine habitat. The branching pattern of the linearized tree suggests to us that eight distinct lineages have seeded the Tanganyika radiation: the Tylochromini, two lineages of the Tilapiini, the Bathybatini, the Trematocarini, the Eretmodini, the ancestor(s) of the Lamprologini, and the ancestor(s) of the H-lineage (sensu Nishida, 1991, but excluding the Eretmodini). The two species of the Tilapiini, Oreochromis tanganicae and Boulengerochromis microlepis, were resolved as separate lineages, in agreement with Klett et al. (2002). The Tanganyikan representatives of the Tylochromini and Tilapiini either were already part of the ancient fauna of the proto-Malagarazi-Congo River before the lake basin formed or entered the lacustrine habitat more recently. The five remaining seeding lineages radiated in step with the development of the current truly lacustrine habitat. Our analyses identified the
Trematocarini and the Bathybatini as seeding lineages. Because both underwent radiation in Lake Tanganyika and no relatives are known in extant river faunas, these endemics may be the only surviving descendants of two ancient African lineages. The same may be true for the Eretmodini and the Lamprologini, which consistently branched before the onset of the primary lacustrine radiation, and for the ancestor of the $\mathrm{H}$-lineage (as above: sensu Nishida, 1991, but excluding the Eretmodini).

\section{The Primary Lacustrine Radiation and the Evolution of Alternative Brood Care Strategies}

The second series of cladogenetic events evident from the linearized tree analysis concerns the primary lacustrine radiaton itself (gray box in Fig. 5). The following lineages are likely to have radiated in parallel: the Lamprologini, the H-lineage (sensu Nishida, 1991, but excluding the Eretmodini), and possibly also the Eretmodini, Trematocarini, and Bathybatini. Earlier studies on the adaptive radiation of Lake Tanganyika cichlids have created conflicting hypotheses for the relationships of the nonmouthbrooding Lamprologini to the H-lineage (Nishida, 1991; Sturmbauer and Meyer, 1993; Kocher et al., 1995). Our present analyses unambiguously placed the Eretmodini as separate seeding lineage from the other six. The Eretmodini comprise four described species of biparental mouthbrooders (but most probably include more species; see Rüber et al., 1999). The remaining six lineages (which we redefine as $\mathrm{H}$-lineage here) were placed as a sister group to the substrate spawning Lamprologini, but they all are mouthbrooders with a wide variety of strategies (Kuwamura, 1986; Keenleyside, 1991). All the Limnochromini and Perissodini are primitive biparental

FIGURE 6. (a) ML tree $(G T R+\Gamma)$ of Lake Tanganyika cichlids and six additional haplochromine taxa from Lakes Victoria and Malawi, based on sequences of the mitochondrial control region (declaring the Eretmodini as outgroup). Numbers above the branches are ML bootstrap estimates; numbers below the branches are the corresponding MP bootstrap estimates (values $<50 \%$ are not shown). Riverine taxa are marked with a gray box, and taxa not shared with the ND2 and cyt $b$ analyses are indicated with asterisks. (b) Results of the likelihoodmapping analysis (Strimmer and von Haeseler, 1997) of the control region dataset, represented as triangles. Values at the corners indicate the percentage of fully resolved quartet topologies, values at the lateral sections give the percentages of partially resolved topologies, and the number in the center of the triangle represents the percentage of unresolved trees. (c) Saturation plot of transition and transversion mutations ( $y$-axis) against the percentage of sequence divergence ( $x$-axis) of 742 pairwise comparisons for the control-region dataset. The slope and the coefficient of determination $\left(R^{2}\right)$ are depicted for transition and transversion mutations. 


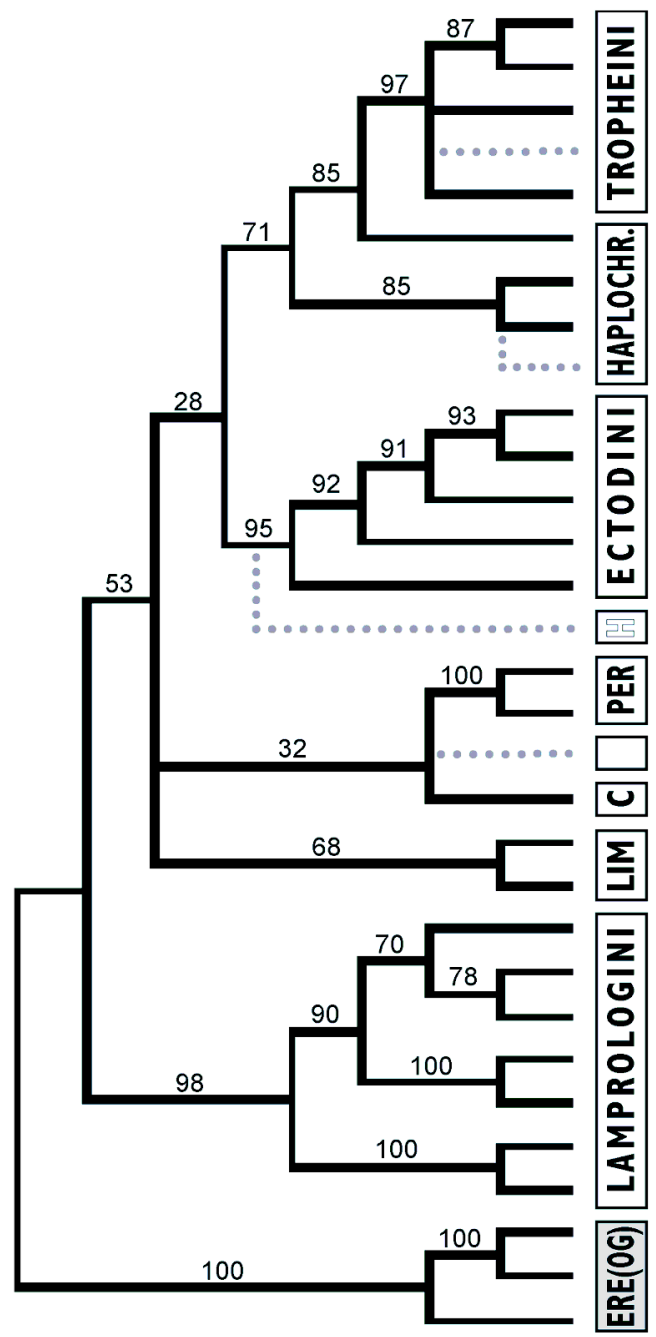

Lobochilotes labiatus

Petrochromis orthognathus*

Pseudosimochromis curvifrons*

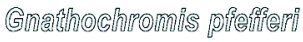

Simochromis babaulti ${ }^{\star}$

Astatotilapia burtoni

Pseudocrenilabrus multicolor

Orthochromis polyacanthus

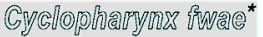

Asprotilapia leptura*

Xenotilapia sima

Microdontochromis tenuidentata*

Aulonocranus dewindti*

Grammatotria lemairii“

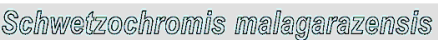

Plecodus straeleni

Perissodus microlepis

Cyp/hơ

Paracyprichromis brieni

Limnochromis auritus

Triglachromis otostigma

Julidochromis marlieri

Neolamprologus brichardi

Telmatochromis bifrenatus

Lamprologus congoensis ${ }^{*}$

Lamprologus mocquardii

Altolamprologus calvus*

Lamprologus callipterus

Tanganicodus irsacae (OG)

Eretmodus cyanostictus (OG)

Spathodus erythrodon (OG)

FIGURE 7. Strict consensus tree of four most-parsimonious trees of 27 taxa based upon 895 bp of the mitochondrial control region combined with a 402-bp segment of $c y t b$, representing all lineages involved in the Tanganyika radiation. Three Eretmodine cichlids (Spathodus erythrodon, Tanganicodus irsacae, and Eretmodus cyanostictus) were declared to be outgroups, on the basis of the results of the higher-level analyses (Fig. 4). The four outlined taxa had a significantly different evolutionary rate and were thus reincluded in a separate analysis after constraining the topology that was obtained without them. Riverine taxa are marked with a gray box; taxa not shared with the ND2 and cyt $b$ analyses are indicated with asterisks. ERE, Eretmodini; OG, outgroup; LIM, Limnochromini; C, Cyprichromini; PER, Perissodini; H, Haplochromini; Haplochr, Haplochromini.

mouthbrooders. They form pairs to spawn, females lay as many as 300 eggs, and both parents guard the fry. The Ectodini comprise both biparental and maternal mouthbrooders, whereas the Cyprichromini are pelagic maternal mouthbrooders producing relatively high numbers of eggs. The Haplochromini and Tropheini are maternal mouthbrooders, producing small numbers of eggs (10-50) and featuring a relatively long time of buccal incubation. Our analyses placed the origin of presumably ancestral biparental mouthbrooders (Limnochromini, Perissodini, and some Ectodini) and of tribes of more derived maternal mouthbrooders (Cyprichromini, Ectodini, Haplochromini, and Tropheini) at the base of the primary lacustrine radiation, although the order of their branching differed in the different analyses. This suggests that the diversification of these six mouthbrooding tribes was connected to a single transition from substrate breeding to mouthbrooding during the primary lacustrine radiation. Subsequently, 
each lineage must have evolved its particular strategy of mouthbrooding in step with its diversification, with some lineages remaining at relatively primitive styles and others reaching highly derived styles (Barlow, 1991; Keenleyside, 1991).

\section{Ecomorphological Diversification and Trophic Adaptations}

A robust phylogenetic hypothesis is essential in studying the evolutionary pathways of traits that allow coexistence of multiple species. In cichlid fishes, dental and pharyngeal specializations of the jaw morphology, as well as dietary specialization, are regarded as the most important factors promoting coexistence (Fryer and Iles, 1972). In the rocky littoral zone of Lake Tanganyika, for example, 50-60 cichlid species live in sympatry or close neighborship (Kawanabe et al., 1997). The potential for coexistence is widely seen in the small but distinct differences in ecology, morphology, and behavior of the different species. In terms of basic ecological segregation, many tribes occupy distinct niches and habitat types (discussed earlier). Given the clear-cut ecomorphological distinctions between all the Tanganyikan tribes (Greenwood, 1984), each major Tanganyikan cichlid lineage must have undergone progressive diversification within a range defined by the initial ecological segregation during the very beginning of the primary radiation. In terms of ecomorphological specializations, the primary lacustrine radiation apparently established a primary division into major ecological guilds within the scope of the lake habitat. However, this observation does not imply that particular trophic specializations evolved in one tribe only. In terms of their trophic specialization, Tanganyikan cichlids can be divided into six major trophic groups: epilithic algal feeders, scale-eaters, piscivores, zoobenthos feeders, planktivores, and omnivores (Yamaoka, 1997). For example, epilithic algae grazers, zooplankton-feeders, and zoobenthos feeders are all found in the tribes Lamprologini, Ectodini, and Tropheini.

\section{Taxonomic and Biogeographic Implications}

As a result of our analyses, the taxonomy of several species needs to be revised. Gnathochromis pfefferi, considered a member of the Limnochromini as is its congener G. permaxillaris, consistently turned out instead to be a member of the Tropheini (in agreement with Kocher et al., 1995). This result is also supported by observations of its breeding behavior, indicating that G. permaxillaris is a biparental mouthbrooder that forms breeding pairs (P. Henninger, pers. comm.), whereas G. pfefferi exhibits a derived mode of maternal mouthbrooding. Another putative member of the Limnochromini, Benthochromis tricoti, was always placed outside this tribe; however, we have analyzed only sequences of the control region for this species, and its exact position remains unresolved. Benthochromis tricoti was resolved as sister to Cyphotilapia frontosa and the Perissodini in the unweighted MP tree but was placed in close relationship to the Cyprichromini in the weighted MP tree and in the ML topology. Future studies including additional genera assigned to the tribe Limnochromini might provide more precise knowledge about the taxonomic integrity of this tribe. Cyphotilapia frontosa, previously considered a member of the Tropheini (Poll, 1986), was confirmed to be a separate lineage (Kocher et al., 1995). We placed C. frontosa as sister to the Limnochromini according to analyses of the proteincoding genes ND2 and cyt b, although bootstrap support was reasonable only in the ML analyses. In the analyses based on the mitochondrial control region, $C$. frontosa was resolved as sister to the Perissodini, but this was not well supported in the bootstrap evaluations. Its previous placement in the tribe Tropheini was largely based on its Tropheuslike pharyngeal apophysis (Poll, 1956). Other features, however, such as its social organization in swarms, its particular muscular extension producing the hump on its head, and its karyotype (J. Snoeks, pers. comm.), support its distinctness from the Tropheini. We thus suggest placing the monotypic genus Cyphotilapia into a new tribe, to be named Cyphotilapiini. To resolve the exact placement of $C$. frontos $a$ in the redefined $\mathrm{H}$-lineage, additional data are required.

Previous research has already shown that Astatoreochromis alluaudi is likely to be sister to several East African riverine congeners and to the haplochromine species flocks of Lakes Victoria and Malawi (Meyer et al., 1990, 1991; Nagl et al., 2000). The genus Astatotilapia was shown to be more closely related to the species flocks of Lakes Victoria and Malawi than to Astatoreochromis. Whereas Astatotilapia calliptera clustered with 
the Lake Malawi cichlids, A. burtoni was placed as sister to the Lake Victoria flock (Meyer et al., 1991). Furthermore, A. burtoni was identified as the sister species of the endemic Tanganyikan tribe Tropheini (Nishida, 1991; Sturmbauer and Meyer, 1993). In all our analyses, the riverine haplochromine genera Astatoreochromis, Astatotilapia, Cyclopharynx, Orthochromis, Pseudocrenilabrus, and Schwetzochromis do not form the most basal branches of the primary lacustrine radiation of the H-lineage. Moreover, indications are strong that they do not represent a monophyletic assemblage together with the Tropheini. In the analyses of the protein-coding genes ND2 and cyt $b$, the representatives of the genera Orthochromis, Pseudocrenilabrus, Astatoreochromis, and Astatotilapia clustered with the Tropheini, but Schwetzochromis malagarazensis was placed outside the remaining haplochromines, suggesting that Schwetzochromis might be the sister group to the Perissodini (Fig. 4a). Only in the weighted MP tree of the control region dataset, with all sequences included, was the Haplochromini/Tropheini assemblage resolved as monophyletic, albeit with low bootstrap support. The unweighted MP analysis of the same dataset identified both Schwetzochromis and a clade comprising the riverine haplochromines Astatoreochromis, Cyclopharynx, and Orthochromis as separate lineages. The ML tree and the MP analysis of the reduced dataset (with reinclusion of four taxa after constraining the topology) also indicated the placement of Schwetzochromis outside the remaining haplochromines, in a sister group relationship to the Ectodini. The inclusion of six haplochromine species from Lakes Victoria and Malawi in the control region dataset, to link the primary lacustrine radiation in Lake Tanganyika to the East African Haplochromini super-flock, led to the placement of these six taxa as sister group to the Tropheini, with Astatotilapia burtoni sister to the representatives of Lake Victoria (Fig. 6a). This outcome suggests that riverine East African haplochromines of the genera Astatotilapia, Astatoreochromis, Cyclopharynx, Orthochromis, and Pseudocrenilabrus, as well as their relatives in Lakes Victoria and Malawi, evolved from an ancestor they share with the endemic Tanganyikan tribe Tropheini. Clearly, more sequence data and a more extensive sample of haplochromines are required to fully understand the total impact of the primary lacustrine radiation in Lake Tanganyika to the radiation of this most species-rich assemblage of cichlid fishes.

\section{Conclusions}

The finding that riverine haplochromines were not placed at the base of the primary radiation of the redefined $\mathrm{H}$-lineage leads us to several suggestions: (1) Riverine haplochromines may not have seeded the radiation but arose within the primary lacustrine radiation of Lake Tanganyika itself; thus, the hypothesis that ancestral riverine haplochromines are the starting point for the primary lacustrine radiation of Lake Tanganyika is not supported. (2) Both the rapid lineage formation during the primary lacustrine radiation and the parallel evolution of various reproductive strategies suggest that this radiation gave rise to six mouthbrooding lineages from a Lamprologus-like substrate spawning ancestor. (3) The ecomorphological diversification of the primary lacustrine radiation in Lake Tanganyika was coupled with the evolution of mouthbrooding.

The primary radiation of Lake Tanganyika most likely took place in a habitat connected ecologically and hydrologically to rivers, permitting the ancestors of riverine haplochromines and lamprologines to leave the protolake(s). Thus, the primary radiation was not restricted to the lacustrine zone itself but repeatedly enriched the cichlid fauna in the rivers and other water bodies, even outside the present lake basin. This evolutionary scenario is consistent with the geological model of the origin of Lake Tanganyika (Tiercelin and Mondeguer, 1991), in which the first stage of the lake is described as a swampy meandering river that slowly is transformed into shallow protolakes. Importantly, we do not propose that all haplochromine cichlids left the lake at an early stage of the radiation, to return at a later time to seed the evolution of the Tropheini. Indeed, several modern haplochromines such as Astatotilapia burtoni live in swamp and marsh areas of Lake Tanganyika (or other East African Lakes) as well as in several rivers around the lake. The ancestor(s) of these haplochromines, which possibly inhabited the same transition zone between rivers and the lake habitat, could thus give rise to the 
endemic Tanganyikan tribe Tropheini (at a later stage of the radiation) as well as to different species flocks in other East African lakes (as is the case in Lakes Kivu, Victoria, and Malawi).

The Lake Tanganyika cichlid species assemblage has so far been viewed as an evolutionary reservoir of old African lineages (Nishida, 1991). Alternatively, it may be viewed as an evolutionary hotspot from which modern African cichlid lineages arose, spreading subsequently to rivers and lakes in other African regions (Sturmbauer et al., 1994). Our new evolutionary hypothesis suggests that both views may in fact be true because part of the species flock is derived from an ancient cichlid fauna that no longer exists elsewhere in Africa. At the same time, the Tanganyikan radiation precipitated a major faunal change in the African cichlid fauna, through the origin and spread of the most species-rich lineage of cichlids, the Haplochromini.

\section{ACKNOWLEDGMENTS}

We thank L. Mwape, R. Shapola, C. Mwelwa, H. Mudenda, M. Nabuyanda, and the team at the Mpulungu Station of the Ministery of Agriculture, Food and Fisheries, Republic of Zambia, for their help during sample collection. We thank A. Brandstaetter, I. Farias, H. Hauffe, and V. Klett for providing unpublished DNA sequences. We are further grateful to P. Henninger for sharing his findings on cichlid breeding behavior and to R. Hanel, R. and G. Rieger, J. and W. Wieser, two anonymous reviewers, associate editor M. W. Westneat, and C. Simon, editor of Systematic Biology, for valuable comments on the manuscript. W.S. was supported by a DOCfellowship of the Austrian Academy of Sciences. A.M. was supported by the U.S. National Science Foundation (grants BSR-9107838 and DEB-9615178), Deutsche Forschungsgemeinschaft, the University of Konstanz, and the Fonds der Chemischen Industrie. C.S. and S.B. were supported by the Austrian Science Foundation (grant 12339-GEN) and the Jubiläumsfonds der Österreichischen Nationalbank (grant 6058). E.V. was supported by the Belgian Science Foundation (FWO-V grant G0109.99) and a DWTC project (2000-2004).

\section{REFERENCES}

BARLOW, G. W. 1991. Mating systems in among cichlid fishes. Pages 173-190 in Cichlid fishes: Behaviour, ecology and evolution (M. H. A. Keenleyside, ed.). Chapman and Hall, London.

BOULENGER, G. 1898. Catalogue of the fresh-water fishes of Africa in the British Museum (Natural History), Vol. 3. British Museum (Natural History), London.

BROWN, W. M. 1983. Evolution of animal mitochondrial DNA. Pages 62-88 in Evolution of genes and proteins (M. Nei and R. K. Koehn, eds.). Sinauer Associates, Sunderland, Massachusetts.
Bruford, M. W., O. HanotTe, J. F. Y. Brookfield, AND T. BURKE. 1998. Multilocus and single-locus DNA fingerprinting. Pages 287-336 in Molecular genetic analysis of populations: A practical approach (A. R. Hoelzel, ed.). Oxford Univ. Press, Oxford.

BUCKLEY, T. R., C. SIMON, H. SHIMODAIRA, AND G. K. CHAMBERS. 2001. Evaluating hypotheses on the origin and evolution of the New Zealand Alpine cicadas (Maoricicada) using multiplecomparison tests of tree topology. Mol. Biol. Evol. 18: 223-234.

COHEN, A. S., K.-E. LEZZAR, J. J. TIERCELIN, AND M. SORGEHAN. 1997. New palaeogeographic and lake-level reconstructions of Lake Tanganyika: Implications for tectonic, climatic and biological evolution in a rift lake. Basin Res. 9:107-132.

DOlPhin, K., R. BELShaW, C. D. L. ORME, AND D. L. J. QUICKE. 2000. Noise and incongruence: Interpreting results of the incongruence length difference test. Mol. Phyl. Evol. 17:401-406.

ECCLES, D. H., AND E. TREWAVAS. 1989. Malawian cichlid fishes: The classification of some haplochromine genera. Lake Fish Movies, Herten, Germany.

FARIAS, I. P., G. ORTI, AND A. MEYER. 2000. Total evidence: Molecules, morphology, and the phylogenetics of cichlid fishes. Mol. Dev. Evol. 288:76-92.

FARIAS, I. P., G. ORTI, I. SAMPAIO, H. SCHNEIDER, AND A. MEYER. 1999. Mitochondrial DNA phylogeny of the family cichlidae: Monophyly and fast molecular evolution of the neotropical assemblage. J. Mol. Evol. 48:703-711.

FARRIS, S. J. 1989. The retention index and the rescaled consistency index. Cladistics 5:417-419.

FRYER, G., AND T. D. ILES. 1972. The cichlid fishes of the Great Lakes of Afrika. T.H.F. Publikations, Inc., Neptune City, NJ.

Goldman, N., J. P. ANDERson, AND A. G. Rodrigo. 2000. Likelihood-based test of topologies in phylogenetics. Syst. Biol. 49:652-670.

Goodwin, N. B., S. BALSHINE-EARN, AND J. D. REYNOLDS. 1998. Evolutionary transitions in parental care in cichlid fish. Proc. R. Soc. London B 265:22652272.

GREENWOOD, P. H. 1979. Towards a phyletic classification of the 'genus' Haplochromis (Pisces, Cichlidae) and related taxa. Part 1. Bull. Br. Mus. Nat. Hist. (Zool.) 35:265-322.

GREENWOOD, P. H. 1980. Towards a phyletic classification of the 'genus' Haplochromis (Pisces, Cichlidae) and related taxa. Part 2. Bull. Br. Mus. Nat. Hist. (Zool.) 39:1-99.

GREENWOOD, P. H. 1984. African Cichlid and evolutionary theories. Pages 141-154 in Evolution of fish species flocks (A. A. Echelle and I. Kornfield, eds.). Univ. of Maine at Orono Press, Orono.

HASEgaWA, M., H. KISHINO, AND T. YANO. 1985. Dating of the human-ape splitting by a molecular clock of mitochondrial DNA. J. Mol. Evol. 22:160174.

Hillis, D. M., J. P. Huelsenbeck, AND C. W. CUNNINGHAM. 1994. Application and accuracy of molecular phylogenies. Science 264:671-676.

HuelsenbeCK, J. P., AND K. A. CRANDAll. 1997. Phylogeny estimation and hypothesis testing using maximum likelihood. Annu. Rev. Ecol. Syst. 28:437466.

JUKES, T. H., AND C. R. CANTOR. 1969. Evolution of protein molecules. Pages 21-132 in Mammalian protein 
metabolism (H. N. Munro, ed.). Academic Press, New York.

KaWANabe, H., M. Hori, AND M. Nagoshi. 1997. Fish communities in Lake Tanganyika. Kyoto Univ. Press, Kyoto.

KeEnleyside, M. H. A. 1991. Parental care. Pages 191208 in Cichlid fishes: Behavior, ecology, and evolution (M. H. A. Keenleyside, ed.). Chapman and Hall, London.

KIMURA, M. 1980. A simple method for estimating evolutionary rate of base substitutions through comparative studies of nucleotide sequences. J. Mol. Evol. 16:111-120.

KLETT, V., AND A. MEYER. 2002. Mitochondrial ND2 phylogeny of tilapines and the evolution of parental care systems in African cichlid fishes. Mol. Biol. Evol. In press.

KLUGE, A. G., AND J. S. FARRIS. 1969. Quantitative phyletics and the evolution of anurans. Syst. Zool. 18:1-32.

KOCHER, T. D., J. A. CONROY, K. R. MCKAYE, AND J. R. StAufFER. 1993. Similar morphologies of cichlid fishes in Lakes Tanganyika and Malawi are due to convergence. Mol. Phylogenet. Evol. 2:158-165.

KOCHER, T. D., J. A. CONROY, K. R. MCKAYE, J. R. STAUFFER, AND S. F. LOCKWOOD. 1995. Evolution of $\mathrm{NADH}$ dehydrogenase subunit 2 in East African cichlid fishes. Mol. Phylogenet. Evol. 4:420-432.

KOCHER, T. D., W. K. THOMAS, A. MEYER, S. V. EDWARDS, S. PÄÄBO, F. X. VillablanCA, AND A. C. Wilson. 1989. Dynamics of mitochondrial DNA evolution in animals: Amplification and sequencing with conserved primers. Proc. Natl. Acad. Sci. USA 86:61966200 .

KOsSWIG, C. 1947. Selective mating as a factor for speciation in cichlid fish of East African lakes. Nature 159:604-605.

KUWAMURA, T. 1986. Parental care and mating systems of cichlid fishes in Lake Tanganyika: A preliminary field survey. J. Ethol. 4:129-146.

LEE, W. J., J. CONROY, W. H. HOWELL, AND T. D. KOCHER. 1995. Structure and evolution of teleost mitochondrial control regions. J. Mol. Biol. 40:1-13.

Levinton, J., C. Sturmbauer, AND J. Christy. 1996. Molecular data and biogeography: Resolution of a controversy over evolutionary history of a pantropical group of invertebrates. J. Exp. Mar. Biol. Ecol. 203:117-131.

LezZar, K. E., J.-J. Tiercelin, M. DE Batist, A. S. COHEN, T. BANDORA, P. VAN RENSBERGEN, C. LE TURDU, W. MIFUndU, AND J. KLERKX. 1996. New seismic stratigraphy and Late Tertiary history of the North Tanganyika Basin, East African Rift system, deduced from multichannel and high-resolution reflection seismic data and piston core evidence. Basin Res. 8:1-28.

MEYER, A. 1993. Phylogenetic relationships and evolutionary processes in East African cichlid fishes. Trends Ecol. Evol. 8:279-284.

MEYer, A., T. D. KOCHER, P. BASASIBWAKI, AND A. C. WILSON. 1990. Monophyletic origin of Lake Victoria cichlid fishes suggested by mitochondrial DNA sequences. Nature 347:550-553.

MEYeR, A., T. D. KOCHER, AND A. C. Wilson. 1991. African fishes. Nature 350:467-468.

MEYER, A., L. KNOWLES, AND E. VERHEYEN. 1996. Widespread distribution of mitochondrial haplotypes in rock-dwelling cichlid fishes from Lake Tanganyika. Mol. Ecol. 5:341-350.
Moritz, C., T. E. Dowling, AND W. M. BROWN. 1987. Evolution of animal mitochondrial DNA: Relevance for population biology and systematics. Annu. Rev. Ecol. Sys. 18:269-292.

NAGL, S., H. TICHY, W. E. MAYER, N. TAKEZAKI, N. TAKAHATA, AND J. KLEIN. 2000. The origin and age of haplochromine fishes in Lake Victoria, East Africa. Proc. R. Soc. London B 267:1049-1061.

NiSHIDA, M. 1991. Lake Tanganyika as an evolutionary reservoir of old lineages of East African fishes: Inferences from allozyme data. Experientia 47:974-979.

NISHIDA, M. 1997 Phylogenetic relationships and evolution of Tanganyika Cichlids: A molecular perspective. Pages 1-24 in Fish communities in Lake Tanganyika (H. Kawanabe, M. Hori, and M. Nagoshi, eds.). Kyoto Univ. Press, Kyoto.

PÄ̈̈вO, S. 1990. Amplifying ancient DNA. Academic Press, San Diego.

POLL, M. 1956. Résultats scientif. Explor. hydrob. blge au lac Tanganika (1946-1947). Poissons Cichlidae, Institut Royal des Sciences Naturelles de Belgique, Rapport Scientifique, Vol. 3, no. 5B.

Poll, M. 1986. Classification des Cichlidae du lac Tanganika. Tribus, genres et aspeces. Acad. R. Belg. Mem. Classe Sci. (Collection in $-8^{\circ}-2^{\circ}$ serie), T. 45(2)1-163.

RENSCH, B. 1933. Zoologische Systematik und Artbildungsproblem. Verh. Dtsch. Zool. Ges. 1933:19-83.

ROsSITER, A. 1995. The Cichlid fish assemblages of Lake Tangyanika: Ecology, behaviour, and evolution of its species flocks. Adv. Ecol. Res. 26:187-252.

RÜBER, L., E. VERHEYEN, AND A. MEYER. 1999. Replicated evolution of trophic specializations in an endemic cichlid lineage from Lake Tanganyika. Proc. Natl. Acad. Sci. USA 96:10230-10235.

SCHOLZ, C. A., AND B. R. ROSENDAHL. 1988. Low lake stands in Lake Malawi and Tanganyika, East Africa, delineated with multifold seismic data. Science 240:1645-1648.

SHIMODAIRA, H., AND M. HASEGAWA. 1999. Multiple comparisons of log-likelihoods with applications to phylogenetic inference. Mol. Biol. Evol. 16:1114-1116.

STIASSNY, M. L. J. 1990. Tylochromis, relationship and the phylogenetic status of the African Cichlidae. Am. Mus. Novit. 2993:1-14.

StiAssnY, M. L. J. 1991. Phylogenetic interrelationships of the family Cichlidae: An overview. Pages 1-35 in Cichlid fishes: Behaviour, ecology, and evolution (M. H. A. Keenleyside, ed.). Chapman and Hall, New York.

STIASSNY, M. L. J. 1997. A phylogenetic overview of the lamprologine cichlids of Africa (Teleostei, Cichlidae): A morphological perspective. South Afr. J. Sci. 93: 513-523.

STRIMMER, K., AND A. VON HAESELER. 1996. Quartet puzzling: A quartet maximum-likelihood method for reconstructing tree topologies. Mol. Biol. Evol. 13:964969.

STRIMMER, K., AND A. VON HAESELER. 1997. Likelihood mapping: A simple method to visualize phylogenetic content of a sequence alignment. Proc. Natl. Acad. Sci. USA 94:6815-6819.

STURMBAUER, C. 1998. Explosive speciation in cichlid fishes of the African Great Lakes: A dynamic model of adaptive radiation. J. Fish. Biol. 53(Suppl. A):18-36.

STURMBAUER, C., B. BERGER, R. DALLINGER, AND M. FÖGER. 1998. Mitochondrial phylogeny of the genus Regulus and implications on the evolution of 
breeding behavior in Sylvoid songbirds. Mol. Phylogenet. Evol. 10:144-149.

StURMBAUER, C., AND A. MEYER. 1992. Genetic divergence, speciation, and morphological stasis in a lineage of African cichlid fishes. Nature 358:578-581.

Sturmbauer, C., AND A. MEYer. 1993. Mitochondrial phylogeny of the endemic mouthbrooding lineages of cichlid fishes of Lake Tanganyika, East Africa. Mol. Biol. Evol. 10:751-768.

Sturmbauer, C., E. VERHEYEN, AND A. MEYer. 1994. Mitochond rial phylogeny of the Lamprologini, the major substrate spawning lineage of cichlid fishes from Lake Tanganyika in eastern Africa. Mol. Biol. Evol. 11:691703.

Sturmbauer, C., E. Verheyen, L. RÜBER, AND A. MEYER. 1997. Phylogeographic patterns in populations of cichlid fishes from rocky habitats in Lake Tanganyika. Pages 97-111 in Molecular systematics of fishes (C. A. Stepien and T. D. Kocher, eds.). Academic Press, San Diego.

Sullivan, J., J. A. MARKert, AND C. W. KilPatrick. 1997. Phylogeography and molecular systematics of Peromyscus aztecus species group (Rodentia: Muridae) inferred using parsimony and likelihood. Syst. Biol. 46:426-440.

SWOFFORD, D. L., G. J. Olsen, P. J. WADDEll, AND D. M. Hillis. 1996. Phylogenetic inference. Pages 407-543 in Molecular systematics, 2nd edition (D. M. Hillis, C. Moritz, and B. K. Mable, eds.). Sinauer Associates, Sunderland, Massachusetts.

SWOFFORD, D. L. 2000. PAUP*: Phylogenetic analysis using prasimony (*and other methods), version 4.0. Sinauer Associates, Sunderland, Massachusetts.

TABORKSKI, M., E. HEART, M. V. SIEMENS, AND P. STOERIG. 1986. Social behavior of Lamprologus species: Functions and mechanisms. Ann. Mus. Roy. Afr. Sci. Zool. 251:7-12.
TAKAHASHI, K., Y. TERAI, M. NiSHIDA, AND N. OKADA. 1998. A novel family of short interspersed repetitive elements (SINEs) from Cichlids: The patterns of insertion of SINEs at orthologous loci support the proposed monophyly of four major groups of cichlids fishes in Lake Tanganyika. Mol. Biol. Evol. 15:391407.

TAKEZAKI, N., A. RZHETSKY, AND M. NEI. 1995. Phylogenetic test of the molecular clock and linearized trees. Mol. Biol. Evol. 12:823-833.

ThOMPSON, J. D., D. G. Higgins, AND T. J. GiBSON. 1994. CLUSTAL W: Improving the sensitivity of progressive multiple sequence alignment trough sequence weighting, position-specific gap penalties, and weight matrix choice. Nucleic Acids Res. 22:46734680 .

TIERCELIN, J.-J., AND A. MONDEGUER. 1991. The geology of the Tanganyika trough. Pages 7-48 in Lake Tanganyika and its life (G. W. Coulter, ed.). Oxford Univ. Press, London.

VERHEYEN, E., L. RÜBER, J. SNOEKS, AND A. MEYER. 1996. Mitochondrial phylogeography of rock-dwelling cichlid fishes reveals evolutionary influence of historical lake level fluctuations of Lake Tanganyika, Africa. Philos. Trans. R. Soc. London B 351:797-805.

YAMAOKA, K. 1997. Trophic ecomorphology of Tanganyikan cichlids. Pages 25-56 in Fish communities in Lake Tanganyika (H. Kawanabe, M. Hori, and M. Nagoshi, eds.). Kyoto Univ. Press, Kyoto.

YANG, Z. 1994. Estimating the pattern of nucleotide substitution. J. Mol. Evol. 39:306-314.

Yoder, A. D., J. A. IRWIN, AND B. A. PAYseUr. 2001. Failure of the ILD to determine data combinability for slow loris phylogeny. Syst. Biol. 50:408-424.

Received 4 May 2000; accepted 29 September 2001 Associate Editor: M. W. Westneat 